\title{
Emerging Corrosion Inhibitors for Interfacial Coating
}

\author{
Mona Taghavikish ${ }^{1}$, Naba Kumar Dutta ${ }^{1,2, *}$ and Namita Roy Choudhury ${ }^{1,2, *}$ \\ 1 Future Industries Institute, University of South Australia, Mawson Lakes Campus, Mawson Lakes, \\ Adelaide, SA 5095, Australia; mona.taghavikish@mymail.unisa.edu.au \\ 2 School of Chemical Engineering, University of Adelaide, Adelaide, SA 5005, Australia \\ * Correspondence: naba.dutta@adelaide.edu.au (N.K.D.) or naba.dutta@unisa.edu.au (N.K.D.); \\ Namita.roychoudhury@adelaide.edu.au (N.R.C.) or namita.choudhury@unisa.edu.au (N.R.C.); \\ Tel.: +61-8830-23546 (N.K.D.); +61-8830-23719 (N.R.C.)
}

Academic Editor: Tony Hughes

Received: 5 September 2017; Accepted: 2 October 2017; Published: 1 December 2017

\begin{abstract}
Corrosion is a deterioration of a metal due to reaction with environment. The use of corrosion inhibitors is one of the most effective ways of protecting metal surfaces against corrosion. Their effectiveness is related to the chemical composition, their molecular structures and affinities for adsorption on the metal surface. This review focuses on the potential of ionic liquid, polyionic liquid (PIL) and graphene as promising corrosion inhibitors in emerging coatings due to their remarkable properties and various embedment or fabrication strategies. The review begins with a precise description of the synthesis, characterization and structure-property-performance relationship of such inhibitors for anti-corrosion coatings. It establishes a platform for the formation of new generation of PIL based coatings and shows that PIL corrosion inhibitors with various heteroatoms in different form can be employed for corrosion protection with higher barrier properties and protection of metal surface. However, such study is still in its infancy and there is significant scope to further develop new structures of PIL based corrosion inhibitors and coatings and study their behaviour in protection of metals. Besides, it is identified that the combination of ionic liquid, PIL and graphene could possibly contribute to the development of the ultimate corrosion inhibitor based coating.
\end{abstract}

Keywords: ionic liquid; polyionic liquid; graphene; hybrid coating

\section{Introduction}

Corrosion of metal is a significant problem, costing worldwide industries more than $\$ 300$ billion annually. The inhibitors minimize the rate of corrosion by forming a thin adsorbed film on metal. In the last decades, much attention has been focused on the need to design and develop new and emerging materials for corrosion protection. As an example, nanomaterials, biomaterials, corrosion inhibitors, sol-gel coatings, self-healing and smart materials. Out of these, self-healing coating and corrosion inhibitors are an emerging and broad field.

A self-healing system is inspired from biological systems that have inherent ability to repair damage via healing mechanisms and is categorized into three types; namely, microencapsulation, vascular based and intrinsic materials [1]. These systems have the ability to repair the damage caused due to mechanical stress or energy and to recover their functionality using resources inherently available to them. On the other hand, corrosion can be inhibited or controlled by introducing a stable protective layer of inert metals, conductive polymers, inorganic compound or monolayers of graphitic or heterocyclic structure between a metal and a corrosive environment. A corrosion inhibitor is a chemical constituent which, when added in small amount to the metal environment, diminishes or controls and prevents corrosion. In the oil and chemical industry, inhibitors are considered as the first line of defense against corrosion. 
In simpler words, corrosion can be defined as failing of materials by chemical process. Among them the most significant is electrochemical corrosion of metals, in which oxidation process $\left(M \rightarrow M^{n+}+n e^{-}\right)$is helped by the presence of a suitable electron acceptor, sometimes referred to in corrosion science as depolarizer. In general, corrosion is a two-step electrochemical process having both anodic and cathodic sites, with flow of charges (electrons and ions), it is conventional in both wet and dry conditions. Wet corrosion is a major problem to tackle; it is a dominating corrosion at or near room temperature and in presence of an electrolyte, or even in presence of water.

Since corrosion process is a surface reaction, addition of corrosion inhibitor in very small concentration to an interfacial layer can prevent or reduce the corrosion rate of a metal exposed in aggressive environment. Generally there are three mechanisms of the corrosion inhibition as given below $[2,3]$ :

- Adsorption: the inhibitor is chemically adsorbed on the surface of the metal and forms a protective thin film with inhibitor effect.

- Surface layer: formation of an oxide film for protection of the metal surface.

- Passivation: the inhibitor reacts with corrosive elements of aqueous media, forming protective precipitates.

Based on the above mechanism of corrosion inhibitors, they can be classified to three different types; cathodic, anodic, and mixed or adsorption type inhibitors. Corrosion inhibitors that cause the delay in the cathodic reaction are known as cathodic inhibitors. Similarly, the anodic inhibitors slow down the anodic reaction. Those inhibitors that affect both the cathodic and the anodic reactions are known as mixed inhibitors, and these inhibitors generally work by an adsorption mechanism and known as adsorption inhibitors. In general, inorganic inhibitors have either cathodic or anodic actions, while organic inhibitors have both cathodic and anodic actions [2] (Figure 1).

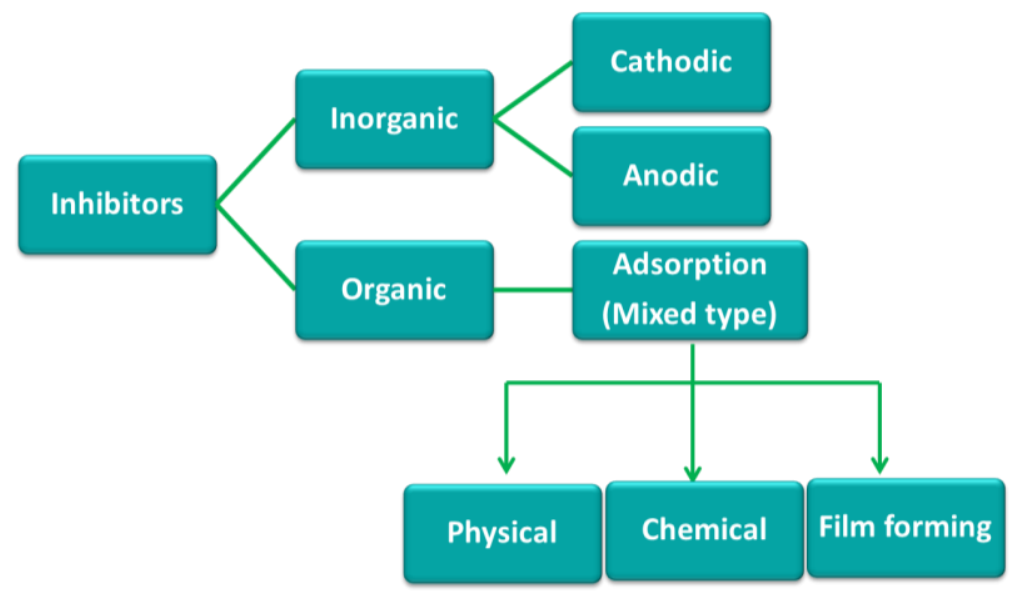

Figure 1. Classification of corrosion inhibitors [2].

Due to the toxicity of inorganic inhibitors, a variety of organic compounds have been used as corrosion inhibitors for the protection of steel specifically in acid medium [4]. In general, organic corrosion inhibitors are more effective than inorganic compounds for protection of steels in acid media. Organic inhibitors work by an adsorption mechanism in which the adsorption of the inhibitor molecule at the metal-solution interface results in formation of a film of inhibitor molecules to protect the surface from the corrosive environment either by physically blocking or by delaying the electrochemical processes [5]. Organic inhibitors generally contain heteroatoms $(\mathrm{S}, \mathrm{O}$, or $\mathrm{N})$ and their efficiency is related to the presence of these atoms in the molecule as well as heterocyclic compounds and $\pi$ electrons $[6,7]$. This is due to the fact that $\mathrm{O}, \mathrm{N}$, and $\mathrm{S}$ are found to have higher basicity and electron density and are the key active centres for the adsorption process on the metal surface. 
Adsorption inhibitors protect the metal following three possible ways: (1) physical adsorption, (2) chemical adsorption and (3) film formation (Figure 1). Physical (or electrostatic) adsorption is a result of electrostatic attraction between the inhibitor and the metal surface. Physically adsorbed inhibitors interact rapidly, but they are also easily removed from the surface. The most effective inhibitors are those that chemically adsorbed (chemisorbed). Chemisorption occurs as a result of charge sharing or charge transfer between the inhibitor molecules and the metal surface. However, chemisorption is slower than physical adsorption process and is not completely reversible [8].

Film formation mechanism is based on the surface reactions of inhibitor molecules and formation of thin film on the surface with blocking both anodic and cathodic areas. Organic inhibitors are able to form a protective hydrophobic film, adsorbed on the metal surface. In fact, the polar group of the organic molecule is directly attached to metal and the nonpolar end is oriented in a vertical direction to the metal surface. Thus, they can prevent diffusion of corrosive species and establish a barrier against chemical and electrochemical attack [6].

Most organic inhibitors contain at least one functional group. The strength of adsorption of organic inhibitors relies on the charge of this group rather on the hetero atom present in the organic molecule. The structure of the rest of the molecule influences the charge density on the functional group [6]. Most common organic inhibitors belonging to different chemical families such as fatty amides [9,10], pyridines [11,12], imidazolines [13,14], other 1,3-azoles [15,16] and polymers [17] have showed excellent performance as corrosion inhibitors.

While a variety of different inorganic and organic compounds can be used as inhibitors, however, the practical application of many of those inhibitors poses risk for environmental protection standards, cost and toxicity. Thus, there is a strong need to develop efficient and environmentally friendly corrosion inhibitors. Among various classes of compounds, ionic liquids (ILs) have attracted considerable attention in recent years as "green material," because of their attractive properties such as chemical and thermal stability, nonflammability, very low or negligible vapour pressure, high ionic conductivity, a wide electrochemical potential window. They can be used as potential inhibitors whose specific interactions with metal can be tailored through choice of their amphiphilic structures or using them in various forms such as microcapsule, gel, emulsion, nanoparticles or using them in synergistic combinations. Due to high sensitivity of the metal-IL interactions, careful design and tailoring of ionic liquid materials play a crucial role for successful corrosion inhibition application.

Another promising material, graphene a single-atom-thick sheet [18], a flat monolayer of carbon atoms tightly packed into hexagonal honey comb lattice in which carbon atom is $s p^{2}$ hybridised has been identified as a next generation inhibitor material for shielding of metal from corrosion as it possesses matchless properties such as excellent thermal and chemical stability, high strength, chemical inertness, permeability to molecules and gases, extremely high aspect ratio, high theoretical specific surface area. From the point of permeability, the hexagonal network of carbon atoms in graphene is so dense that no known material can penetrate through it. However, there are a number of critical challenges related to application of graphene on various metals, which needs significant attention. To date, graphene coatings on metals have been employed using chemical vapour deposition (CVD) or transfer techniques involving high energy consumption, special expensive tools, high temperatures, careful treatments and multistep processes. Such techniques (CVD or transfer) are cumbersome, uneconomical and not very practical for large scale application. On the other hand, there are significant advantages if graphene can be deposited from preformed ink, which is reproducible, and can be used to coat objects of any dimensions as in conventional paints or coatings.

Thus, the key focus of this review is to present and discuss some important results on the physico-chemical properties of the emerging corrosion inhibitors based on IL and graphene to advanced coating applications. Before the presentation of these results, a precise description of the synthesis, characterisation, structure-properties relationship and performance of IL and graphene based inhibitors suitable for anticorrosion applications is given below. 


\section{Ionic Liquid (IL) Based Corrosion Inhibitors}

Among all the different types of synthetic materials, a new class of low toxicity organic compounds known as Ionic liquids (ILs) deserves particular attention due to their rapid growth in a number of applications, they have shown effective performance as inhibitors for various metals and alloys $[19,20]$. In this section, an insight into ionic liquids will be discussed in detail.

ILs are the low-melting organic salts that are composed of cations and anions that melt below $100{ }^{\circ} \mathrm{C}$ [21,22]. The first IL was investigated in 1914 by Paul Walden with his observation on ethylammonium nitrate $\left(\left[\mathrm{EtNH}_{3}\right]\left[\mathrm{NO}_{3}\right]\right)$ with very low melting point of $13-14{ }^{\circ} \mathrm{C}$ [21]. Due to the unique properties such as low toxicity, negligible vapor pressure, high thermochemical and electrochemical stabilities, non-flammability, and their ability to act as catalyst, ILs have been used in a large number of applications as an eco-friendly alternative to substitute volatile organic solvents including catalysis [23], separation processes [24,25], analytics [26], lubricants [27], and electrochemical applications [28]. Common ionic liquids are formed by an organic cation (i.e., ammonium, imidazolium, pyridinium, pyrrolidinium, phosphonium, sulfonium) in combination with a complex anion (Scheme 1) [29].

Cations<smiles>[R]N1[C-]CN([R])C1</smiles><smiles></smiles>

N-alkylpyridinium 1,3-dialkyl-
imidazolium

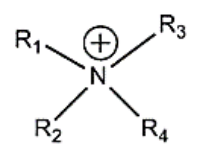

Tetraalkylammonium<smiles>[R]P([R])([2H])([2H])[2H]</smiles>

Tetraalkylphosphonium

$$
\text { hydrophobic }
$$

Anions

$$
\begin{aligned}
& {\left[\mathrm{PF}_{6}\right]^{-}} \\
& {\left[\left(\mathrm{CF}_{3} \mathrm{SO}_{2}\right)_{2} \mathrm{~N}\right]^{-}} \\
& {\left[\mathrm{BR}_{1} \mathrm{R}_{2} \mathrm{R}_{3} \mathrm{R}_{4}\right]^{-}}
\end{aligned}
$$

hydrophilic

$\left[\mathrm{NO}_{3}\right]^{-} \mathrm{Cl}^{-}, \mathrm{Br}^{-} \mathrm{I}^{-}$

$\left[\mathrm{CF}_{3} \mathrm{CO}_{2}\right]^{-}$

$\left[\mathrm{CH}_{3} \mathrm{CO}_{2}\right]^{-}$

Scheme 1. Most commonly used cations and anions in various ILs.

The common configuration of ILs consists of an amphiphilic group with a long chain, hydrophobic tail, and a hydrophilic polar head [30]. Therefore, due to their molecular configuration, they are able to form micelles and lowering interfacial tension of aggressive media, resulting in an enhancement in surface wetting and adsorption [30-32]. These properties of ILs have a useful effect on surface exposure and may be responsible for the corrosion inhibition of metals. ILs compounds are reported to show corrosion resistant behavior on copper, mild steel and aluminum. Here some of the literature examples will be discussed.

Espinosa et al. [31] studied the corrosion rate and surface interaction of oxygen-free high conductivity (OFHC) copper with two protic ammonium ionic liquids and four aprotic imidazolium species in order to investigate the best candidate for lubricant applications or as precursors of surface coatings. The protic ILs, with no heteroatoms in their composition, are the triprotic di[(2-hydroxyethyl) ammonium] succinate (MSu) and the diprotic di[bis-(2-hydroxyethyl)ammonium] adipate (DAd). The four aprotic ILs contain imidazolium cations with short or long alkyl chain substituents and reactive anions: 1-ethyl-3-methylimidazolium phosphonate ([EMIM]EtPO $\left.{ }_{3} \mathrm{H}\right)$; 1-ethyl-3-methylimidazolium octylsulfate ([EMIM] $\mathrm{C}_{8} \mathrm{H}_{17} \mathrm{SO}_{4}$ ); 1-hexyl-3-methylimidazolium tetrafluoroborate ([HMIM] $\mathrm{BF}_{4}$ ) and 1-hexyl-3-methylimidazolium hexafluorophosphate ([HMIM] $\left.\mathrm{PF}_{6}\right)$. As it has been depicted in summary of results in Figure 2, the lowest corrosion rate is observed for the DAd, which gives low mass $(\Delta m)$ 
and surface roughness changes $\left(\Delta S_{\mathrm{a}}\right)$ and forms adsorbed layers on copper, while MSu forms a dark blue corrosion product by reaction with copper.

\begin{tabular}{|c|c|c|c|c|}
\hline Ionic liquid & O hours & 168 hours & \multicolumn{2}{|c|}{ Final dry } \\
\hline MSu & & 4 & \multicolumn{2}{|c|}{$0,+3$} \\
\hline \multicolumn{5}{|l|}{ DAd } \\
\hline \multicolumn{5}{|l|}{$\mathbf{b}$} \\
\hline Ionic liquid & \multicolumn{2}{|c|}{ Contact angle $\left({ }^{\circ}\right)$ (standard deviation) } & $\Delta \mathrm{m}(\%)$ & $\Delta \mathrm{Sa}(\%)$ \\
\hline MSu & \multicolumn{2}{|l|}{$31.75(1.19)$} & -1.40 & 225 \\
\hline Dad & \multicolumn{2}{|l|}{$62.67(2.19)$} & -0.04 & -3.0 \\
\hline
\end{tabular}

Figure 2. (a) The OFHC copper change during the tests; (b) Contact angles, mass $(\Delta m)$ and surface roughness $\left(\Delta S_{\mathrm{a}}\right)$ changes of MSu and DAd after $168 \mathrm{~h}$ (Reprinted with permission from [31]. Copyright 2013 Elsevier).

Results show that DAd IL remains colourless during the corrosion tests (Figure 2a) and no precipitates are formed on the copper surface, while MSu forms a dark blue corrosion product that completely covers the copper surface at the end of the test. SEM observation showed more roughness in the case of use of MSu and the presence of oxygen and carbon peaks in EDX analysis. Nevertheless, EDX analysis of DAd shows only the presence of copper. They concluded that the presence of proton donor and acceptor sites in the DAd molecules can form a hydrogen bonded network which as a result will improve their lubricating performance. Moreover, all imidazolium aprotic ILs react with copper, with different results as a function of the anion.

Zhang et al. [20] reported the corrosion inhibition effect of 1-butyl-3-methylimidazolium chlorides (BMIC) and 1-butyl-3-methylimidazolium hydrogen sulfate ([BMIM] $\mathrm{HSO}_{4}$ ) on mild steel in $1 \mathrm{M}$ $\mathrm{HCl}$. As a result, it has been concluded that the inhibiting efficiencies decreased in the order of $[\mathrm{BMIM}] \mathrm{HSO}_{4}>\mathrm{BMIC}$. Potentiodynamic polarization studies indicated that addition of both ILs affects both anodic metal dissolution and also cathodic hydrogen evolution reactions. Thus, those ILs could be classified as mixed type inhibitors. Also, they found that the mechanism of ILs corrosion inhibition is following the Langmiur adsorption isotherm with the high value of adsorption equilibrium constant. Since, the absolute values of standard free energy of adsorption $\left(\Delta G_{\text {ads }}\right)$ in presence of the studied inhibitors were calculated to be less than $40 \mathrm{~kJ} \mathrm{~mol}^{-1}$, it has been expected the inhibitors to be physically adsorbed on the metal surface. The corrosion inhibition properties of three different imidazoline based ILs on aluminium in $1 \mathrm{M} \mathrm{HCl}$ and $0.5 \mathrm{M} \mathrm{H}_{2} \mathrm{SO}_{4}$ were investigated by Quraishi et al. [33] The weight loss study indicated that the inhibition efficiency increased with increase in the concentration of the inhibitor. Moreover, the mechanism of adsorption followed the Langmuir isotherm and behaved as mixed type inhibitors. The most extensively studied IL is based upon the imidazolium cation [31,34,35]. It was observed that the high inhibition efficiency of such inhibitors depends on the specific interaction between the functional groups of IL and the metal surface, due to the presence of the $-\mathrm{C}=\mathrm{N}-$ group and electronegative nitrogen in the structure of the imidazolium coating [36]. Our indepth review of recent literatures shows that it is important to understand and establish the relation between ILs molecular structure, the counterion, the length of substituted alkyl chains and the functional groups 
adsorbed on the metallic surface and corrosion inhibition. In next section, the effect of ILs' structure on the inhibition performance has been presented with literature examples.

\subsection{Effect of IL Structure on Corrosion Inhibition}

\subsubsection{Cation Effect}

Among many kinds of ionic liquid, imidazolinium and pyridinium cations based ILs have been investigated intensively. Shi et al. [37] synthesized a series of new imidazolium ionic liquids and investigated the relationship between the alkyl connecting with $\mathrm{N}(3)$ of imidazolium ring and corrosion inhibition performance in acidic solution. The inhibition efficiency was found to increase with increasing the carbon chain length of the alkyl connecting with $\mathrm{N}(3)$ of imidazolium ring. In another study, the corrosion inhibition behaviour of three synthesized imidazolium ionic liquids with similar chemical structure (namely 1-butyl-3-methylimidazolium chlorides, 1-hexyl-3-methylimidazolium chlorides and 1-octyl-3-methylimidazolium chlorides) on aluminum in hydrochloric acid has been investigated [36]. It has been reported that corrosion of aluminum in aqueous solution depends on the concentration of anions in solution. A general mechanism for the dissolution of aluminum as reported in the literature is [38]:

$$
\begin{gathered}
\mathrm{Al}(\mathrm{s})+\mathrm{H}_{2} \mathrm{O} \rightleftharpoons \mathrm{AlOH}_{\mathrm{ads}}+\mathrm{H}^{+}+\mathrm{e}^{-} \\
\mathrm{AlOH}_{\mathrm{ads}}+5 \mathrm{H}_{2} \mathrm{O}+\mathrm{H}^{+} \rightleftharpoons \mathrm{Al}^{3+}+6 \mathrm{H}_{2} \mathrm{O}+2 \mathrm{e}^{-} \\
\mathrm{Al}^{3+}+\mathrm{H}_{2} \mathrm{O} \rightleftharpoons[\mathrm{AlOH}]^{2+}+\mathrm{H}^{+}
\end{gathered}
$$

In the presence of chloride ions the reaction corresponds to:

$$
[\mathrm{AlOH}]^{2+}+\mathrm{Cl}^{-} \rightarrow[\mathrm{AlOHCl}]^{+}
$$

It is well known that imidazolium group as well as nitrogen atom in heteroaromatic ring of imidazolium compounds can be protonated in acidic solutions. Thus, the interaction of the protonated imidazolium ionic liquid molecules on the aluminum surface competes with the interaction of the ions in the solution. The adsorption of inhibitors on the aluminum surface removes or depletes some of the water molecules originally adsorbed on to the surface, which blocks the formation of $\mathrm{AlOH}_{\text {ads }}$. Thus, both the oxidation reaction of $\mathrm{AlOH}_{\mathrm{ads}}$ to $\mathrm{Al}^{3+}$ and the complexation reaction between the hydrated cation $[\mathrm{AlOH}]^{2+}$ species and chloride ions can be prevented. Moreover, these protonated molecules also compete with the hydrogen ions that can reduce hydrogen evolution. In this case, adsorption would have occurred through polar centers of nitrogen atom in the $-\mathrm{C}=\mathrm{N}-$ group. Meanwhile, the presence of the electron donating group $(\mathrm{Cl})$ on the imidazolium base IL increases the electron density on the nitrogen of the $-\mathrm{C}=\mathrm{N}-$ group, resulting in high inhibition efficiency [20]. This particular effect is evidenced more with the increase in chain length of the alkyl connecting with $\mathrm{N}(3)$ of imidazolium cationic ring.

In another study, Likhanova et al. [29] reported the inhibition action of imidazolium and pyridinium bromide ILs on mild steel in $1 \mathrm{M} \mathrm{H}_{2} \mathrm{SO}_{4}$ at room temperature. Since these ILs affected both anodic and cathodic reactions they are classified as mixed type inhibitor. Scheme 2 represents the inhibition mechanism of the interaction between the ionic liquids and the metallic surface. The adsorption of hydronium $\left(\mathrm{H}_{3} \mathrm{O}^{+}\right)$ion and desorption of hydrogen gas $\left(\mathrm{H}_{2}\right)$ occurs on the cathodic sites whereas the adsorption and desorption of $\mathrm{Br}^{-}$and $\mathrm{SO}_{4}^{2-}$ ions occurs on the anodic sites. The protonated imidazolium or pyridinum molecules are electrostatically adsorbed on the cathodic sites in competition with the hydronium ions available to reduce hydrogen evolution [29].

Since cations of ILs are bigger than hydrogen cations, alkyl chain and aromatic ring cover a large part of the metallic surface and lead to the water molecule displacement from surface. Both imidazolium and pyridinum based ILs show a reasonable corrosion inhibition with average corrosion efficiency within $82 \%-88 \%$ at $100 \mathrm{ppm}$ to protect the mild steel corrosion in the aqueous 
solution of sulphuric acid; their efficiencies are increased with the inhibitor concentration in the range 10-100 ppm. However, due to the larger steric effect of imidazolium ion in comparison to pyridinium, which results in a higher surface coverage area during the chemical adsorption process, imidazolium based IL provides a better inhibition effect than pyridinium.

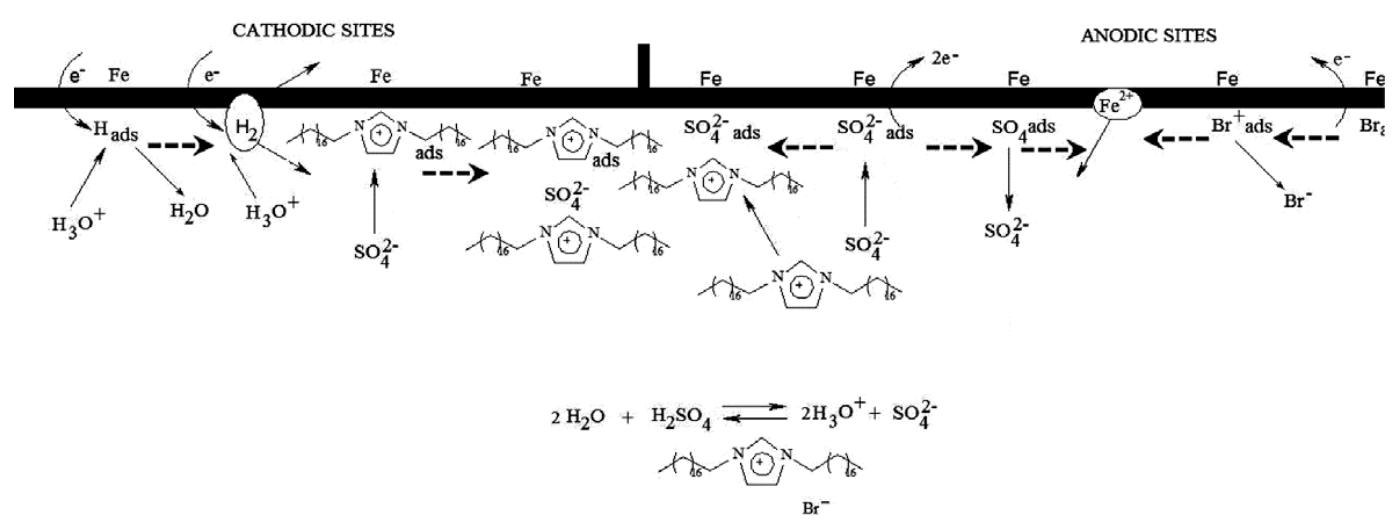

Scheme 2. Corrosion inhibition mechanism of imidazolium and pyridinum molecules on steel surface in $1 \mathrm{M} \mathrm{H}_{2} \mathrm{SO}_{4}$ (Reprinted with permission from [29]. Copyright 2010 Elsevier).

\subsubsection{Anion Effect}

For carbon steel and aluminium, the corrosivity of IL media strongly depends on the chemical structure of the cationic moiety and the nature of anion in the IL molecule. Specifically, the corrosion resistance of carbon steel in water-free ILs strongly depends on the IL anion. Depending on the type of IL, carbon steel may undergo severe corrosion in diluted IL media. Anions like tosylate and dimethyl phosphate generally trigger higher corrosivity specifically in water-diluted ILs. In this regard, Uerdingen et al. [39] investigated the behaviour of carbon steel, austenitic stainless steel, nickel-based alloy, copper, brass and aluminium in presence of various diluted ILs with different concentrations under flow conditions at temperatures up to $90^{\circ} \mathrm{C}$. The effect of the chemical structure of the IL cation and the nature of anion on the corrosivity of the metals has been studied. It is observed that diluted ILs (with water) could result in hydrolysis of IL's anions. As a result, they can produce acids (e.g., sulfuric acid, phosphoric acid) and, hence, cause a considerable increase of medium corrosivity, whereas in water-free ILs, most of the metals exhibited a high corrosion resistance.

Ashassi-Sorkhabi et al. [40] studied the effect of IL anion in corrosion inhibitor behaviour of two synthesized imidazolium ionic liquids with chlorides and hydrogen sulphate anion on mild steel in hydrochloric acid. In the structure of the imidazolium bases, the atoms of the imidazolium ring and the $-\mathrm{C}=\mathrm{N}-$ group can form a big $\pi$ bond. Then, in addition to the $\pi$ electron of the imidazolium, bases enter unoccupied orbitals of iron. The $\pi^{*}$ orbital can also accept the electrons of $d$ orbitals of iron to form bonds, that produce more than one center of adsorption action. Moreover, the presence of the $\mathrm{Cl}$ and $\mathrm{S}$ on the imidazolium structure, which are electron donating groups, increases the electron density on the nitrogen of the $-\mathrm{C}=\mathrm{N}$ - group, resulting in high inhibition efficiency. Therefore, in this study hydrogen sulphate counter-anion showed better inhibiting effect of mild steel in $\mathrm{HCl}$ compared with chloride anion.

\subsection{Synergistic Corrosion Inhibition Using ILs}

As it has been discussed, one of the important advantages of ILs is the ability to select both the anion and cation to have useful properties for a particular application. Due to this feature of ILs and organic salts, they could be used as new organic inhibitors, ideally with synergistic effects. A number of publications have investigated the use of biologically safe anions and cations to produce a salt that could approach the performance of chromates, while being environmentally friendly. 
Recently, Somers et al. [41] described such a family of ILs and organic salts that target dual activity by incorporating both anions and cations with proven evidence of effective inhibition. These salts were based on the imidazolinium cation with carboxylate anions. The imidazolinium has a similar structure to imidazolium with a difference in the $\mathrm{C} 4-\mathrm{C} 5$ double bond saturation on the core ring of the imidazolinium. Depending upon the nature of the anion in the salts, these materials were found to have interesting physical properties such as facile ion transport, as well as demonstrating synergistic corrosion inhibition on mild steel. In this study, the influence of $\mathrm{pH}$ on the corrosion inhibiting performance of the organic salt for mild steel in chloride environments has been investigated.

It has been shown that this environmentally friendly organic IL remains highly active at $\mathrm{pH} 2$ and 8 , which are common environments in which corrosion protection is required. Also at higher $\mathrm{pH}$, the inhibition was controlled by the anion, and the solution showed a high level of protection. Although both the IL's components were mainly ineffective on their own at low $\mathrm{pH}$, the combined salt still had an inhibition efficiency of $72 \%$, indicating a strong synergy between the two ionic species under these conditions. Figure 3 shows an optical microscope image of mild steel samples with corrosion product intact after immersion for $24 \mathrm{~h}$ in salt solutions at different $\mathrm{pH}$. Also, at a $\mathrm{pH}$ of 8 , Figure $3 \mathrm{a}, \mathrm{b}$ show much less corrosion product, but still show some local attack on the sample in the inhibitor containing solution. At a pH of 2 many bubbles have been observed due to the hydrogen gas evolution, where the sample at $\mathrm{pH} 2$ with inhibitor does not show any bubbles, suggesting a significant reduction in the rate of reaction. The samples immersed in the neutral condition show a similar trend to those at a $\mathrm{pH}$ of 8 , where the inhibited solution showed much less corrosion product but still with signs of localized attack.

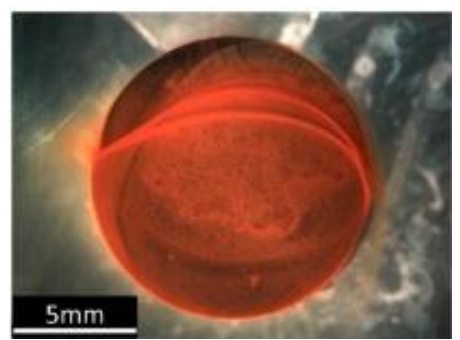

(a)

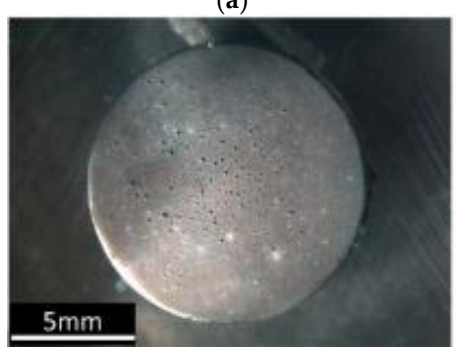

(c)

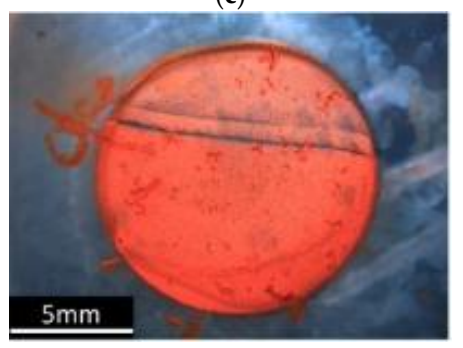

(e)

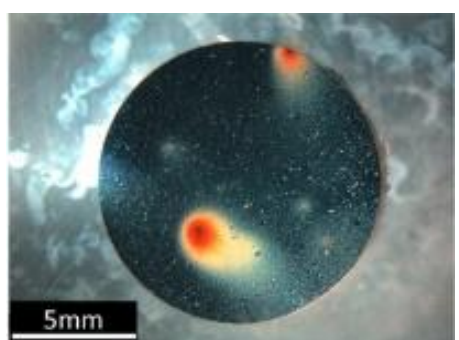

(b)

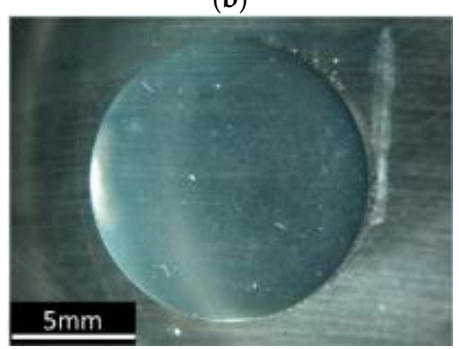

(d)

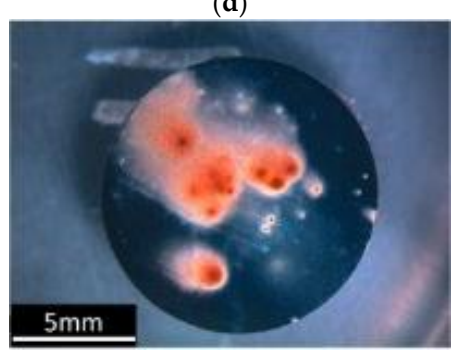

(f)

Figure 3. Optical images of the surfaces of mild steel samples after immersion for $24 \mathrm{~h}$ in (a) $\mathrm{NaCl}$ at pH 8; (b) $\mathrm{NaCl}$ and inhibitor at $\mathrm{pH} 8$; (c) $\mathrm{NaCl}$ at $\mathrm{pH} 2$; (d) $\mathrm{NaCl}$ and inhibitor at $\mathrm{pH} 2$; (e) $\mathrm{NaCl}$ neutral; and (f) $\mathrm{NaCl}$ and inhibitor in neutral (Reprinted with permission from [41]. Copyright 2016 American Chemical Society). 
Such synergy, however, is not always achievable due to some limitation of ILs. One main disadvantages of ILs is unfavourable transport properties of these solvents, which generally present higher viscosity and surface tension than conventional organic solvents [42,43]. Also, once ILs are applied into a coating, they pose problem of miscibility with a coating formulation. For these reasons, polymerized ionic liquids or poly (ionic liquid)s (PILs) are considered more favorable than their monomers in the field of corrosion inhibitor. This is due to their low sensitivity to salts, high shear and thermal stability, high resistivity to strong acid and their efficiencies at lower concentrations. Moreover, such PIL could act as reservoir for IL with controlled release characteristics, such as the microcapsulation of inhibitor which can prevent miscibility issue with other components of coating formulation. Also, they act as controlled release type inhibitor. In the following section detail study of PILs structure and chemistry will be reviewed.

\section{Poly Ionic Liquid (PIL) Based Corrosion Inhibitor}

A special type of polyelectrolytes which carry an IL species in each of the repeating units are referred to polymerized ionic liquids or poly (ionic liquid)s (PILs), and have been proposed as alternative inhibitor materials. Thus, PILs consist of the cationic or anionic centres on their repeating units in the polymer chain (Figure 4) [29]. Although ILs are in a liquid state near room temperature, PILs are in fact solid in most cases, except a couple of exceptions [44]. Nevertheless, opposite to solid polyelectrolytes, PILs have a reportable glass transition temperature in most cases, being well below usual ionic glasses. The major advantages of using a PIL instead of an IL are the enhanced mechanical stability, improved processability, durability, and spatial controllability over the IL species. The combination of properties of ionic liquids with the flexibility and properties of macromolecular structure results in the unique properties for PILs, which can be used in various applications including solid ionic conductor, powerful dispersant and stabilizer, absorbent, premises for carbon materials, permeable polymers, etc. [45-47]. The initial research of PILs goes back to the 1970s. The major design efforts towards developing novel PILs are focused on vinylimidazolium based PILs with diverse functional substituents due to the positive charge being on an aromatic ring and adjacent to the vinyl groups [48-51]. Intensive studies on PILs significantly expanded the research scope of PILs. New structures, properties and applications have been spotted, which generate several valuable branches for researchers. Meanwhile, there are numbers of reviews, which discussed the synthesis of some PILs and introduced the application of PILs, especially imidazolium based PILs in the field of polymer science [45,52].

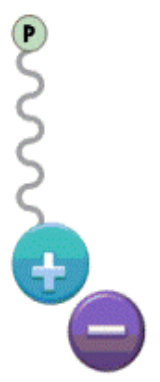

(a)

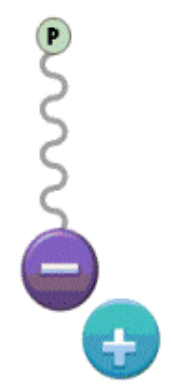

(b)

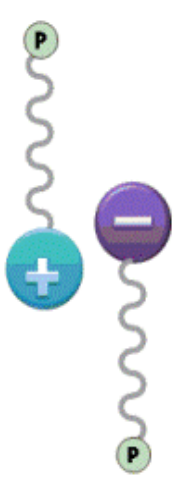

(c)

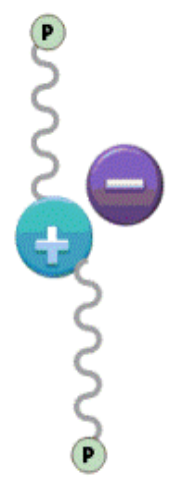

(d)

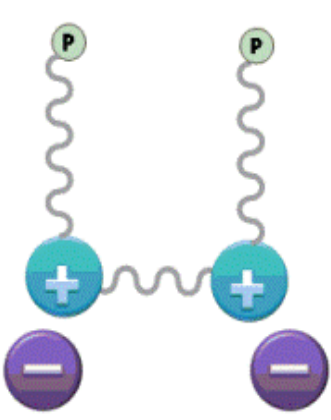

(e)

Figure 4. Basic polymerizable IL monomers. "p" represented of a polymerizing unit in an IL monomer. One polymerizable unit located on the cation (a) or anion (b). Two polymerizable units separated in the cation and anion $(\mathbf{c})$, or located on the cations $(\mathbf{d}, \mathbf{e})$. 
It should be noted that despite the very interesting properties of PILs and their wide range of applications, these eco-friendly compounds have received little interest as corrosion inhibitors. It has been reported that some ILs based on imidazolium, pyridinium and pyridazinium exhibited corrosion inhibition properties for the corrosion of various metals [21], however; there is very limited investigation for application of PILs as a corrosion inhibitors. Here, a few recent work in this area will be discussed. Olivares-Xometl and co-workers reported the poly(ionic liquid)s (PILs), derived from imidazole with different alkylic chain lengths for corrosion inhibition of aluminum alloy in diluted sulfuric acid [53]. Figure 5 shows the likely mechanism of PILs' interaction with both the metallic surface and the aggressive environment. The interaction among the hydrophobic parts of the PILs molecules could support the protective action. However, it is more likely that the main chains of the polymer form an obstacle, which may have a supportive action on inhibition, as they hinder the passage of water and aggressive ions, in agreement with their hydrophobic nature. When the alkyl side chain is composed of 12 carbons, more effective steric hindrance prevalent, as it can interact with the other lateral alkylic groups to slow molecular diffusion.

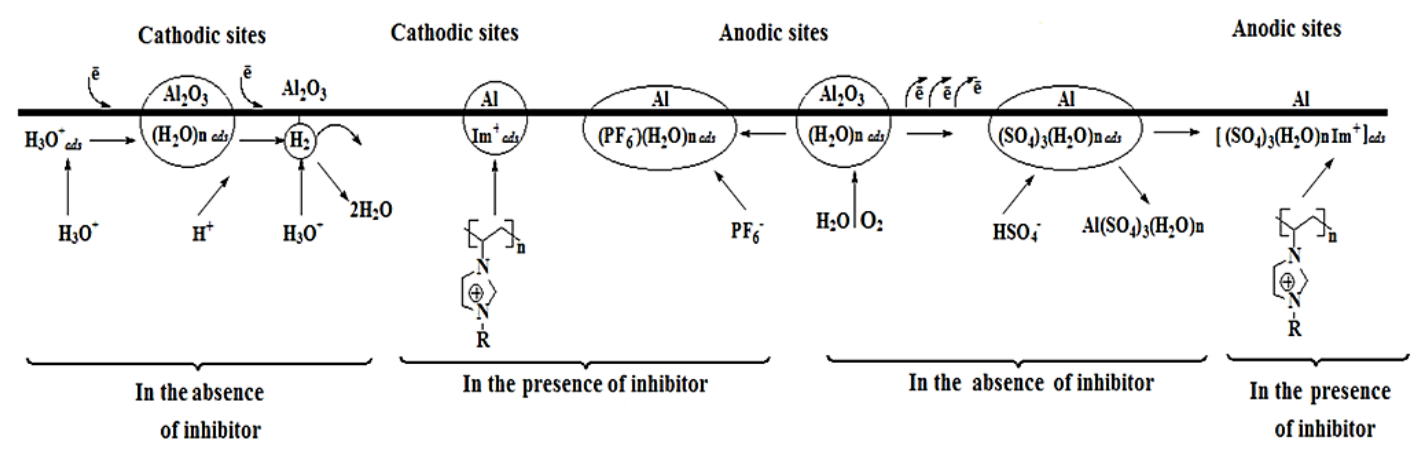

Figure 5. Schematic representation of corrosion and inhibition of aluminum alloy before and after PIL addition in diluted sulfuric acid [53].

However, in this study PILs displayed a short protection range for the alloy. Thus, these PILs are not suitable to be applied in acidic media, as they are not easily adsorbed due to ionic competition, which leads to the formation of a non-uniform corrosion inhibitor film on the aluminum alloy surface. In another study, by Ayman et al. [54,55] PIL based on 2-acrylamido-2 methylpropane sulfonic acid, showed an excellent corrosion inhibition performance for steel in $1 \mathrm{M} \mathrm{HCl}$ medium. The adsorption of IL on steel surface blocked the active centers, which lowered the corrosion rate of steel. It has been reported that introducing oxyethylene ammonium counter ion into the ionic liquid polymer system promotes the wetting characteristics to form anticorrosion protective layer at the solid surfaces [54]. Also, it has been indicated that PIL in this system behaved as a mixed type inhibitor and acted via adsorption on steel surface by hindering and retarding the active centers from the corrosion reaction.

\subsection{PIL Structure Diversity}

There have been persistent efforts devoted to the preparation of PILs in various forms and dimension scales like spherical micro-/nanoparticles, micro-/nanogels, vesicles, nanoworms, etc. [56]. Therefore PILs have a diverse chemical structure reservoir. The most recent forms of PILs, which have been mostly used in different applications, are PIL colloidal particles and PIL gels. An insight into these types of PILs and their characteristic features is presented in the following section.

\subsubsection{PIL Colloidal Particles}

Since colloidal systems have a close connection with nature and human life, PIL colloids are a new platform to investigate the unique properties of ILs with the rather small dimension and the superior dispersity of colloidal particles. Moreover, they setup a powerful platform for 
a variety of studies on PIL functions and applications. A colloidal system is defined as a state of subdivision dispersed in a medium with at least one dimension between approximately $1 \mathrm{~nm}$ and $1 \mu \mathrm{m}$ [57]. Recently, nanostructured PILs, and especially colloidal nanoparticles, have received significant interest as functional polymer nanoparticles. This is due to the fact that small particle sizes increase surface effects on the interfacial interaction and mass/energy transport. Moreover, a small particle size and the charged character of PILs improve the colloidal stability in aqueous as well as non-aqueous dispersions. So far, a few synthetic routes have been developed to prepare PIL nanoparticles including suspension polymerization [58], water-in-oil concentrated emulsion polymerization [59], and precipitation polymerization in water without stabilizers using ionic liquid monomers with long alkyl chains has been recently reported [60,61]. Among PIL nanoparticles a significant focus in this field is on the nanostructured imidazolium-type PILs [47,62]. One of the examples of this type of applications is the work by Yang et al. [63], which reported the preparation of the crosslinked poly(1-butyl-3-vinylimidazolium bromide) microspheres with the diameter of about $200 \mathrm{~nm}$ synthesized via miniemulsion polymerization for application as metal scavenging and catalysis.

In another work by Zhou et al. [64], a thermosensitive type ionic microgels was obtained via the surfactant-free emulsion copolymerization of 1-vinylimidazole and 4-vinylpyridine with thermosensitive monomer $\mathrm{N}$-isopropylacrylamide. The obtained microgels were spherical in shape with narrow size distribution and exhibited thermosensitive behaviour with unique features of PILs in aqueous solution (Figure 6).

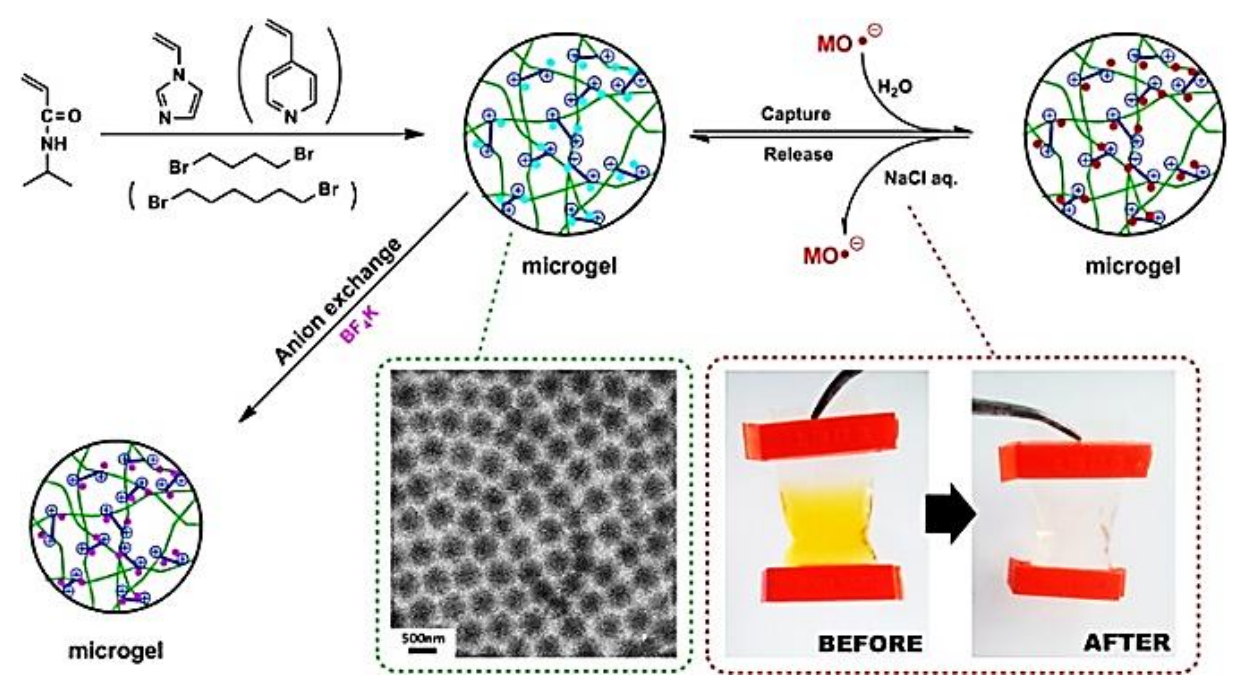

Figure 6. Schematic summary of synthesis of thermosensitive ionic microgels via quaternized crosslinking reaction and their properties (Reprinted with permission from [64]. Copyright 2014 American Chemical Society).

One of the most common methods used for the fabrication of polymer nanoparticles with the droplet sizes typically in the range of $20-200 \mathrm{~nm}$ is miniemulsion. The use of water as the dispersion medium is one of the main advantages of this system, which makes it environmentally friendly and also allows excellent heat dissipation during the polymerization process [65]. On the other hand, very recently, "click" polyaddition reactions in miniemulsions, specifically thiol-mediated chemistry (i.e., thiol-ene/yne, thiol-Michael); have attracted attention as one of the facile methods for synthesis of polymer nanoparticles, and nanocapsules dispersion in heterophase media with high efficiency [66,67]. For example, for the first time Jasinski and co-workers reported the preparation of poly (thioether ester) latex nanoparticles using miniemulsion thiol-ene photopolymerization. Their synthesis was performed in water, at ambient temperature, and without the use of any organic solvent. The resultant linear poly (thioether ester) particles had an average diameter of $130 \mathrm{~nm}$ [68]. 
In another recent work, sub-100 nm crosslinked polythioether nanoparticles were synthesized via thiol-ene photopolymerization in miniemulsion using high-energy homogenization [65]. Our group recently reported the facile preparation of cross-linked PILs based nanoparticles via thiol-ene photo-polymerization in miniemulsion [69]. In this study, the PIL nanoparticles exhibited improved corrosion inhibition properties to the sol-gel coating due to the interaction between the $-\mathrm{C}=\mathrm{N}-$ group and electronegative nitrogen in the PIL with the metal surface.

\subsubsection{PIL Gel}

As described above, PIL gels are one form of PILs which recently have been used in a number of applications such as electrolytes for batteries and supercapacitors [70], drug delivery [71], agriculture, and biomedical fields [72]. Indeed, they are showing a multitude of characteristics that make them very versatile materials with tuneable properties. Gordon and co-workers pioneered the synthesis of large PIL beads in the micron meter size scale through direct polymerizations of 1-butyl-3-vinylimidazoium TFSI in presence of a 1,8-di(vinylimidazolium)-octane TFSI as a crosslinker. Furthermore, the resulting gel-type beads were swelled in acetone, and loaded with palladium nanoparticles to catalyze $\mathrm{C}-\mathrm{C}$ coupling reactions [58]. The authors suggested the application of such gel beads in catalysis, separation technology, and ion-exchange resins. Xiong and co-workers [73] reported a facile one-step synthetic strategy for the preparation of cross-linked polymeric nanogels by the conventional radical copolymerization of a phosphonium-based IL for use as catalysts. Recently, Rahman et al. used a microfluidic method to fabricate monodisperse spherical PIL microgel beads [74]. The authors showed the anion exchange can enable fine-tuning of size and swellability of these beads. By incorporating diverse anions, they were able to impart a multitude of functionalities to these beads, ranging from redox capabilities, controlled release of payload, magnetization, toxic metal removal and robust, reversible $\mathrm{pH}$ sensing. These chemically switchable stimulus-responsive PIL beads have potential applications in portable and preparative chemical analysis, separations and spatially addressed sensing (Figure 7) and also have potential for use as cargo for corrosion inhibitors or slow release inhibitor.

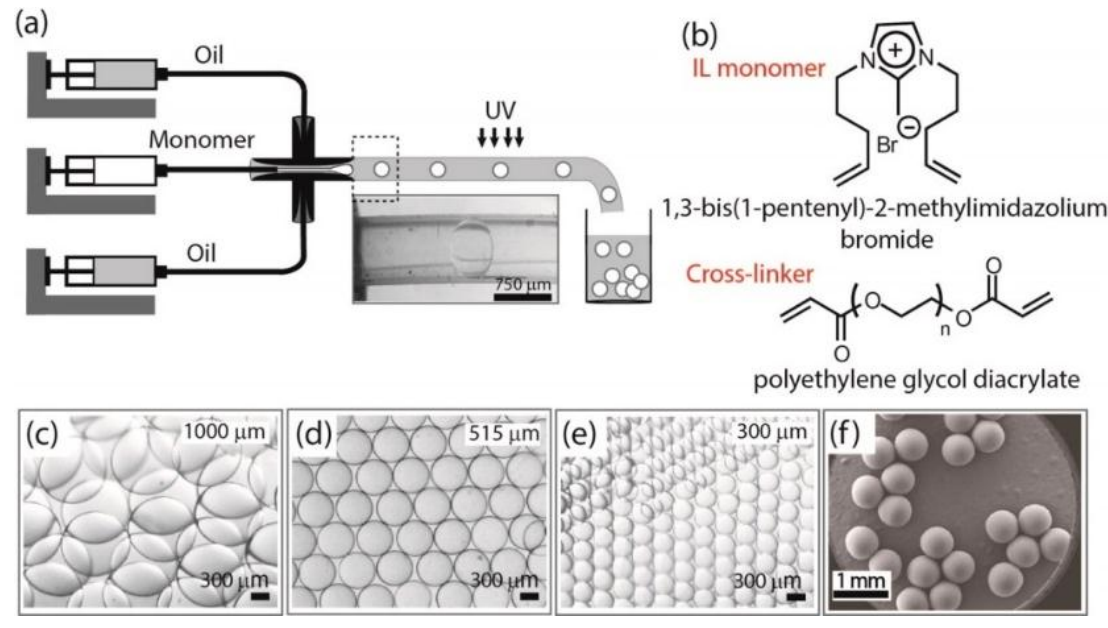

Figure 7. Schematics illustrating microfluidic method to generate switchable stimulus-responsive PIL microgels. (Reprinted with permission from [74]. Copyright 2013 American Chemical Society). (a) Stereomicroscope image of a prepolymer droplet flowing in the transparent capillary tube; (b) Chemical structures of IL monomer and cross-linker; (c-e) Stereomicroscope images of PIL microgels showing their monodispersity and transparency and (f) FESEM image of synthesized PIL[Br].

With the aim of using such PIL as corrosion inhibitors, we reported the novel and facile fabrication of multifunctional PIL gel beads using vinyl imidazolium based ionic liquid through click-type reactions (Figure 8) [75]. A detailed study into the effect of reactant ratios is examined. 
The gel formation is confirmed through fourier transform infrared spectroscopy (FTIR), thermal analysis, and kinetic studies. These PIL gels exhibited multiple characteristics including (1) self-healing characteristics due to their rubbery nature, (2) the ability to uptake active molecules which acts as corrosion inhibitors, and (3) $\mathrm{pH}$ sensing through the incorporation of indicator molecules. These functionalities demonstrate the potential of PIL gel family as multifunctional autonomous platform material for the control, detection and inhibition of corrosion.

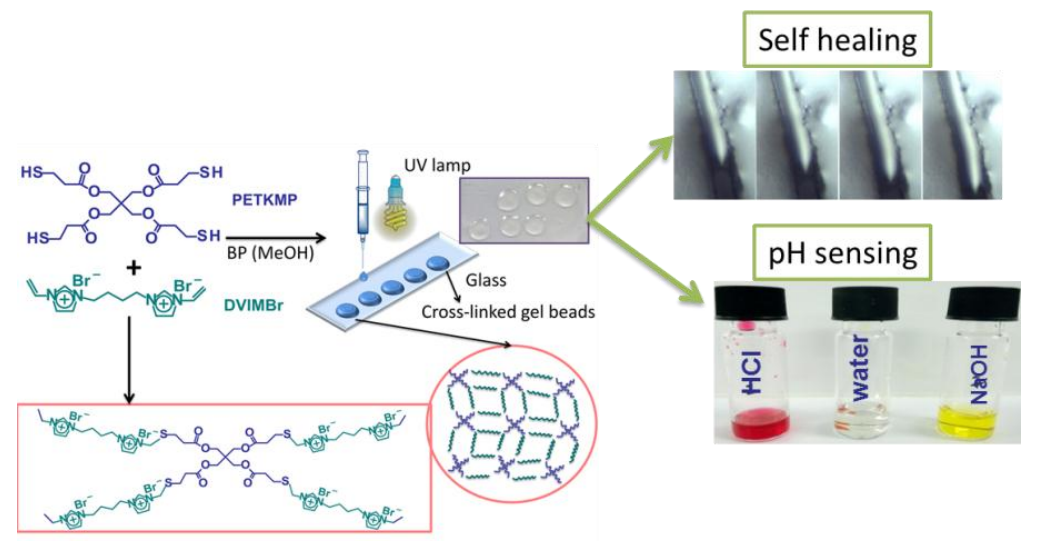

Figure 8. The facile fabrication of multifunctional PIL gel beads using vinyl imidazolium based ionic liquid through click-type reactions. (Reprinted with permission from [75]. Copyright 2015 American Chemical Society).

\section{Graphene as Green Corrosion Inhibitor in Anticorrosion Coating}

Graphene is a nanofiller with one-atom-thick planar sheet of two-dimensional carbon with $s p^{2}$ bonded carbon atoms that are densely packed in a honeycomb crystal lattice or an unrolled single-walled carbon nanotube [76]. Different approaches for preparing graphene sheets have been investigated like graphite exfoliation, including mechanical cleavage of graphite, chemical exfoliation of graphite, thermal-induced exfoliation, and direct synthesis, such as epitaxial growth, and bottom-up organic synthesis. Prasai et al. [77] studied the corrosion inhibition effect of copper and nickel by either growing graphene on these metals by chemical vapor deposition (CVD) method, or by mechanically transferring multilayer graphene onto them (Figure 9). Graphene grown by chemical vapour deposition (CVD) technique has shown superior anticorrosion coating but it is also demonstrated that these coating cannot be used over a long-term duration. It has been reported that transferring multiple graphene layers onto the metal surfaces will increase the degree of protection with building thicker and more robust films.
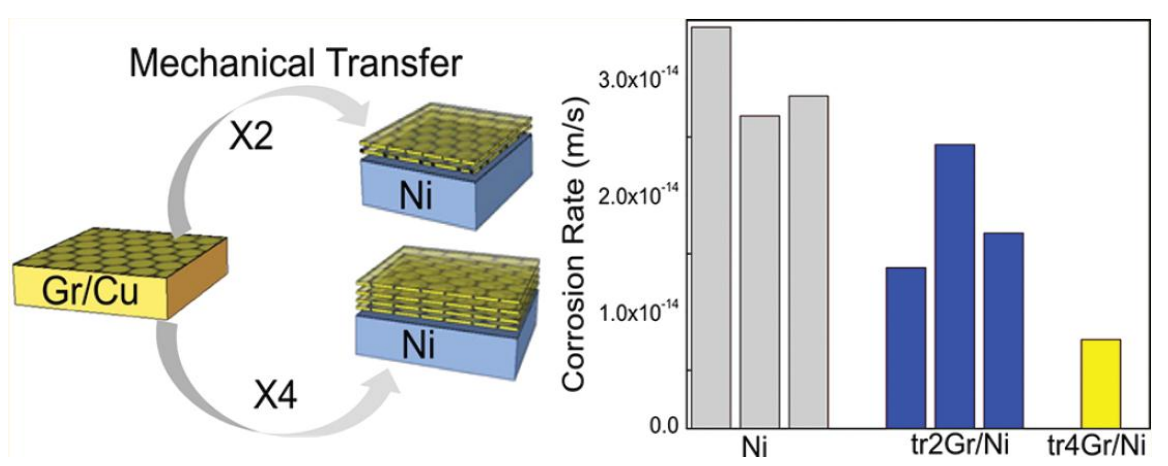

Figure 9. Schematic demonstration of thin layers of graphene as a protective coating that inhibits corrosion of underlying metals. (Reprinted with permission from [77]. Copyright 2012 American Chemical Society). 
High thermal conductivity, better gas barrier, extraordinary electronic transport properties, superior mechanical stiffness combined with a wide set of other unusual properties of graphene-based composites made them promising and cheaper alternative to carbon nanotubes-based composites [78-81]. Graphene and graphene derivatives (e.g., graphene/graphite oxide, functionalized graphene, etc.) could be used in various applications such as hydrogen storage [82], sensors [83], transparent conductive films [84], batteries [85,86], super capacitors [87], solar cells [88] and nanocomposites coatings [89-91]. Due to the high surface area of graphene sheet $\left(2630 \mathrm{~m}^{2} / \mathrm{g}\right)$, improvement of mechanical, thermal, and electrical properties of composite graphene based coating could be achieved with very low loading [92]. Chang et al. [93] applied polyaniline/graphene composites (PAGCs) for corrosion inhibition of steel. The composites display outstanding barrier properties against $\mathrm{O}_{2}$ and $\mathrm{H}_{2} \mathrm{O}$. Figure 10 depicts the corrosion inhibition behaviour of bare steel and PAGCs coated steel with different amount of graphene loading in a corrosive medium ( $3.5 \mathrm{wt} \%$ aqueous $\mathrm{NaCl}$ electrolyte) under potentiodynamic polarization conditions. As it can be observed, as the PAGCs loading was increased further, the corrosion inhibition ability was enhanced evidenced by the highest $E_{\text {corr }}$ and lowest $I_{\text {corr }}$ values (which corresponds to a lower corrosion rate). In fact, using graphene in coating matrix could increase the length of the diffusion pathways for reactive gases such as oxygen and water vapour in polymer coatings and lead to a remarkable improvement of the corrosion inhibition of metallic substrate compared to normal polymer coating.

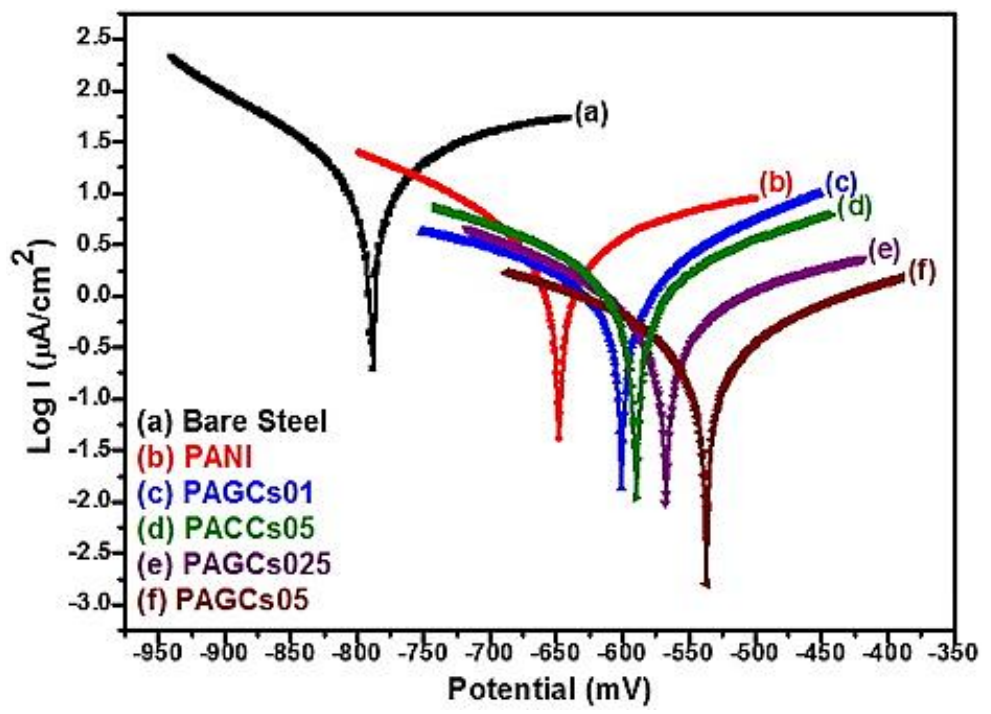

Figure 10. Tafel plots for (a) bare steel; $(\mathbf{b}, \mathbf{c}, \mathbf{d}, \mathbf{e}, \mathbf{f})$ PANI-coated with different amount of graphene loaded. Electrodes measured in $3.5 \mathrm{wt} \% \mathrm{NaCl}$ aqueous solution (Reprinted with permission from [93]. Copyright 2012 Elsevier).

Wang et al. [79] suggested that incorporation of graphene sheets into the epoxy polymer composite improved thermal conductivity and reduced coefficients of thermal expansion (CTEs). Their results also indicate that due to the high thermal-stability of graphene, they can be used in microelectronics coating applications. Since it is easy to obtain the graphene precursor, graphite, as it is naturally abundant, and the functionalized graphene can serve as a conductive nanofiller for other polymers (such as epoxy, polyimide, polyurethane, etc.), polymer/graphene based composite coatings will emerge as a new area of corrosion inhibition technology.

Stronger interface have been achieved using graphene platelets (GP) comprising one or more layers of a graphene plane. Yasmin et al. [94] have developed epoxy/graphite nanocomposites by mixing epoxy with graphite in solvent; 4 wt \% graphite increases Young's modulus by $10 \%$ and glass transition temperature $\left(T_{\mathrm{g}}\right)$ marginally from 143 to $145^{\circ} \mathrm{C}$. Better results have been obtained using sonication and shear mixing, $1 \mathrm{wt} \%$ GP increasing modulus $15 \%$, but leads to a reduction of 
tensile strength. The mechanical properties of epoxy/GP nanocomposites have been investigated by Koratkar et al. [95] showing improvement in epoxy fracture toughness from 0.97 to $1.48 \mathrm{MPa} \mathrm{m}^{1 / 2}$ at $0.1 \mathrm{wt} \%$ filler fraction. Therefore, it could be used as toughening agent for coating.

Despite the tendency of graphene nano-sheets to re-aggregate and stack due to their high surface area and strong van der Waals force has limited their applications in polymer nanocomposites. However, several studies have focused on improving the dispersion and interface interaction of graphene in a polymeric matrix using functionalised graphene. Novel method for functionalization of GP has been presented by Miller [96] using a coupling agent to form covalent bonding between fillers and soft matrix (0.78 GPa Young's modulus), resulting in 50\% modulus improvement at $1 \mathrm{wt} \%$ filler fraction. Chiang and Hsu [97] have improved the fire resistance of epoxy/GP nanocomposite following a similar method. Martin-Gallego et al. [98] studied the effect of functionalized graphene sheets (FGS)/epoxy coatings which are prepared using cationic photopolymerization on mechanical properties of coating. Their results indicate increased stiffness and $T_{\mathrm{g}}$ values of the cured epoxy network with better storage modulus properties in higher temperature.

Jeong and co-workers [99] investigated the effect of graphene content on structures and electrical properties of graphene/epoxy composite films which are prepared by solution casting and following thermal curing of diglycidyl ether of bisphenol-A with an amine-functionalized agent mixed on a polyimide film. The graphene/epoxy composite films can be utilized as high performance electric heating elements in various applications. They found that the graphene content as well as the applied voltage are two key elements in controlling the maximum temperatures of the composite films. Bao et al. [100] enhanced the mechanical, electrical and thermal properties of the epoxy nanocomposites utilizing functionalized graphene oxide. In situ thermal polymerization has been used to functionalize graphene oxide (FGO) via surface modification by hexachlorocyclotriphosphazene and glycidol. Strong interfacial interaction between FGO and epoxy matrix improved the thermal stability, storage modulus and hardness in a polymeric matrix.

Thus, graphene as an anti-corrosive agent is very attractive as it may protect metals by keeping their intrinsic properties, which cannot be achieved using three dimensional protective paints, oxides or polymers. In the field of using graphene as corrosion protective material the biggest hurdle is that the graphene sheets synthesised using current methods still contain too many defects. So the main challenge in near future is to improve the quality of sheet produced, the poor quality of sheet drastically reduces the performance as an anti-corrosive material. The keys factors affecting the quality of sheets are defects or abnormalities in graphene sheets like:

- Missing bonds;

- Pentagonal and hexagonal lattices;

- Lattice distortion;

- Local thickness variations;

- Presence of impurities.

All these factors can represent the centre of damage accumulation also, other than altering the properties of graphene. Local defects can lead to accumulation of oxygen which ruins the chemical properties of sheet. Presently the functionalization of GO via non-covalent and covalent route with organic compounds has become a matter of rigorous research for production of innovative hybrid nano composites with new advanced functions and applications.

\section{Quantum Chemical Methods as Efficient Tools to Study Corrosion Inhibitors}

Quantum chemical methods are seen to be very effective in determining the molecular structures as well as explaining the electronic structures and reactivity's of molecules. Computational chemistry is considerably used to assess the efficiency of corrosion inhibitors, this method helps to search compounds of desired property employing computational modelling. Quantum chemical method and molecular modelling techniques help in defining a large number of molecular parameters illustrating 
the reactivity, shape, and binding properties of complete molecules as well as of individual molecular fragments and substituents. The prominent quantum chemical parameters are atomic charges, molecular orbital energies ( $E_{\mathrm{HOMO}}, E_{\mathrm{LUMO}}$ and $\left.\Delta E_{\text {gap }}\right)$, dipole moment, charge distribution. Density functional theory has successfully been applied to explain the importance of structure of corrosion inhibitors and their adsorption efficiency on the metal surfaces, however the properties of corrosion inhibitors like $E_{\mathrm{HOMO}}, E_{\mathrm{LOMO}}, \Delta E_{\text {gap }}$, dipole moment $(\mu)$, electronegativity $(\varkappa)$, and atomic charge have by far achieved the appropriate correlation with corrosion inhibition efficiency.

\section{Emerging Embedment Methods of Corrosion Inhibitors}

Corrosion inhibitors can be incorporated into the coating formulation through different ways. One of the most commonly used methods is the direct addition of inhibitors in the primer or topcoat. However, a too high concentration or low solubility of the inhibitors often results in a deterioration of the integrity and physical barrier properties of the matrix of the protection system [101]. In addition, the existing interaction of the inhibiting agents with the protective matrix often leads to significantly reduced stability of the protective layer and the deactivation of the inhibitors. Recently, different new methods for inhibitor incorporation have emerged to prevent the direct interaction of inhibitor with the matrix. One of the most common methods is application of inhibitor loaded coatings. Coatings based on inhibitor loaded containers protect the metal by releasing corrosion inhibitor in response to changes in the coating integrity (cracks) or local environment ( $\mathrm{pH}$ shift) caused by corrosion attack. These systems have been extensively investigated, because they are potential replacements for the banned chromate-based coatings [102]. Out of these, self-healing coating is an emerging and broad field to replace the chromate for corrosion control and autonomic repair of coatings (self-healing), which is discussed in this section.

\subsection{Self-Healing Coating}

Coating with self-healing properties is an advanced application of emerging corrosion inhibitors. The concept of self-healing which is initiated in the nineties by Dry [103] and Sottos [104] is the known phenomena seen in the nature and refers to self-repair. Self-healing coatings can be classified into two main classes' namely (1) extrinsic and (2) intrinsic self-healing systems. In extrinsic self-healing systems such as capsule-based and vascular systems, the healing agents are added as a separate phase into the matrix, while intrinsic systems such as ionomers, hydrogen-bonded systems, etc., are those which are free from healing agent and do not require any external energy to trigger the response $[105,106]$. They can repair the mechanical damage spontaneously due to the architecture of the molecules themselves and avoiding rupture and corrosion of underlying substrate. Extrinsic technique possesses several advantages over intrinsic, which will be discussed in this section.

In contrast to conventional anticorrosion coating, emerging corrosion inhibitor embedded in self-healing coating can act in response to corrosion attack, decrease the corrosion rate thereby enabling less maintenance and durability of the coating. For achieving this goal, the coatings have to provide release of the active and repairing material rapidly after integrity changes in coating. The main idea is to load active agents (e.g., corrosion inhibitors) into nanocontainers surrounded by a shell which controlled the permeability and then to introduce them into the coating matrix. Consequently, nanocontainers are keeping corrosion inhibitor in a "trapped" state and distributing uniformly in the passive matrix. Thus, the undesirable interaction between the corrosion inhibitor (active material) and the passive matrix which leads to spontaneous leakage could be prevented. When the local environment undergoes changes or if the active surface is affected by the outer impact, the nanocontainers respond to that signal and release encapsulated inhibitor. Various methods to add the self-healing properties to coatings have been investigated including encapsulation, reversible chemistry, microvascular networks, nanoparticle phase separation, polyionomers, hollow fibres, and monomer phase separation [107]. Microvascular is a strategy in which material with interconnected series of network channels has been designed. In this approach, circulatory system continuously 
transports the necessary chemicals and building blocks of healing to the site of damage. Therefore, coating on a substrate containing a micro channel network is healed. This is the most biomimetic approach and it is difficult to achieve practically and at large scales in synthetic materials. Nanotubes are another approach that may be able to deliver larger amounts of liquid healing agent to the crack plane. Halloysites (aluminosilicate nanotubes) which are one of the most abundant natural nanotubes have recently been applied as containers in the automotive and maritime industries for corrosion protection. They have been developed as an entrapment system for loading, storage, and controlled release of corrosion inhibitor in coatings [108]. The drawbacks of using nanotubes lie in its poorly defined composition and its narrow particle size [107]. So far the most successful approach in self-healing the polymeric component of organic coatings is microencapsulation. This approach has significant advantages including protection of reactive materials (inhibitors) from corroding environment, controlled evaporation of inhibitors, safe handling of toxic inhibitors and controlled release of the inhibitors for delayed release or long acting release [109].

\subsubsection{Encapsulated Type Self-Healing}

Corrosion inhibitors can be easily embedded into the capsules through variety of techniques. These techniques can be merged into two main categories; physical and chemical (Figure 11) [1]. There are different chemical approaches for synthesizing the microcapsules such as interfacial polymerization [110], coacervation, in situ polymerization [111,112], extrusion, and sol-gel methods. The fastest and most convenient method among them is in situ polymerization. In this approach, microcapsules containing healing agent (inhibitor) in a trapped state disperses uniformly in the matrix containing a catalyst capable of polymerizing the healing agent and fracture upon loading of the coating, releasing the low viscosity self-healing reagents to the damaged area for curing and filling of the micro cracks (Figure 11) [113,114].

Brown et al. [112] are known as a pioneer of the micro-/nanocapsules synthesis with their achievement of micro capsulation of dicyclopentadiene (DCPD) as a healing agent with urea-formaldehyde (UF) shell using in situ polymerization. Most commonly used healing agents as a core are dicyclopentadiene (DCPD), epoxy, linseed oil, tung oil, o-dichlorobenzene and dimethyl siloxane. Shell materials are mainly limited to poly(urea-formaldehyde) (PUF) and poly(melamine-formaldehyde) (PMF) or melamine modified poly(urea-formaldehyde) (MUF) [114]. Table 1 summarises recent work that has been carried out in microcapsulation based self-healing system for coating applications.

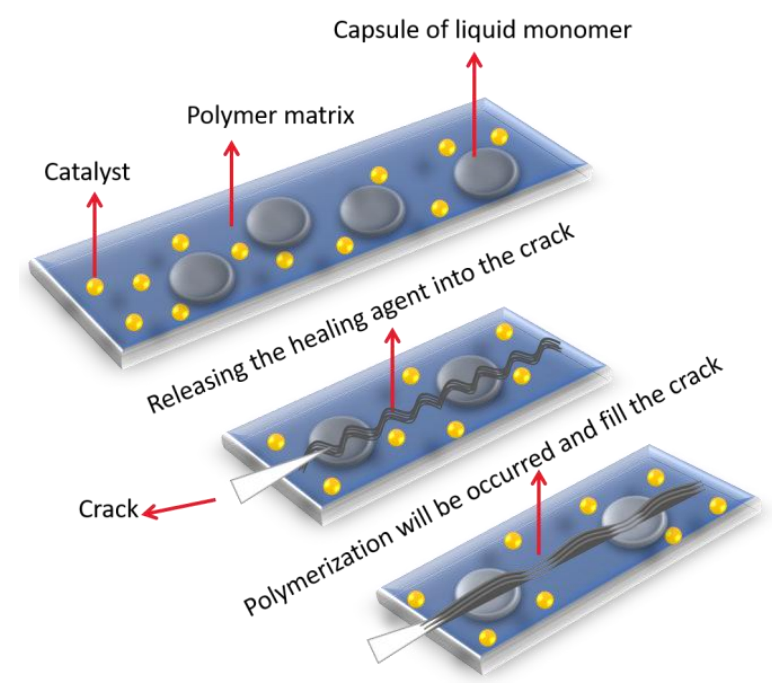

Figure 11. Encapsulated type self-healing through in situ polymerization technique. 
Table 2 is the summary of characteristics which will be required for designing microencapsulationbased self-healing polymeric materials [115]. It is crucial to consider four steps process of achieving healing ability to obtain better functionality: storage, release, transport, and rebonding. Each of these steps depends significantly on the chemistry and properties of the healing agent system [107]. Table 2 reveals the importance to develop capsules with good compatibility with the coating matrix and considering the possibility to encapsulate and upkeep active material, and control of the permeability properties of the shell through external stimuli. Shell permeability could be changed reversibly or irreversibly by various stimuli: variation of the $\mathrm{pH}$, ionic strength, temperature, ultrasonic treatment, alternating magnetic field and electromagnetic irradiation.

As a result, different responses can then be observed, such as tuneable permeability or more drastic ones like total rupture of the container shell. Also as it has been shown in this table, size of the capsules is another important parameter which should be less than $300-400 \mathrm{~nm}$; capsules of larger size can reduce the protective performance of the coating [107].

Table 1. Summary of most recent work in microcapsule based self-healing.

\begin{tabular}{|c|c|c|c|c|}
\hline $\begin{array}{l}\text { Microcapsule Components } \\
\text { (Core and Shell) }\end{array}$ & Chemistry & Specific Feature & $\begin{array}{l}\text { Size of } \\
\text { Capsule }\end{array}$ & Ref. \\
\hline $\begin{array}{c}\text { Shell: polysulphone } \\
\text { Core: 1-hexyl-3- } \\
\text { methylimidazolium } \\
\text { bis(trifluoromethylsulphonyl) } \\
\text { imide [HMIM][NTf2] ionic liquid }\end{array}$ & $\begin{array}{c}\text { Solvent } \\
\text { evaporation. }\end{array}$ & $\begin{array}{l}\text { Chemically stable within the } \\
\text { high-temperature curing } \\
\text { conditions necessary for the } \\
\text { coating system (up to } \\
\text { approximately } 380^{\circ} \mathrm{C} \text { ). }\end{array}$ & Below $10 \mu \mathrm{m}$ & $\begin{array}{l}\text { Magalhães et al. } \\
\text { [116] }\end{array}$ \\
\hline $\begin{array}{l}\text { Shell: poly(urea-formaldehyde) } \\
\text { Core: } 1 \mathrm{H}, 1 \mathrm{H}, 2 \mathrm{H}, 2 \mathrm{H}- \\
\text { perfluorooctyl } \\
\text { triethoxysilane (POTS) }\end{array}$ & $\begin{array}{l}\text { In situ } \\
\text { polymerization }\end{array}$ & $\begin{array}{l}\text { good corrosion protection ability } \\
\text { to steel; self-healing behaviour } \\
\text { was realised under ambient } \\
\text { condition without any } \\
\text { manual intervention }\end{array}$ & $100 \mu \mathrm{m}$ & Huang et al. [111] \\
\hline $\begin{array}{c}\text { Shell: ethylene glycol } \\
\text { dimethacrylate (EGDM) } \\
\text { Core: ionic liquid, } \\
\text { 1-hexyl-3-methylimidazolium } \\
\text { bis(trifluoromethane } \\
\text { sulfonyl)amide }\end{array}$ & $\begin{array}{l}\text { Self-assembling of } \\
\text { phase separated } \\
\text { polymer } \\
\text { (SaPSeP method) }\end{array}$ & $\begin{array}{l}\text { ionic conductivity; good results in } \\
\text { corrosion protection }\end{array}$ & $\begin{array}{l}\text { Multi hollow } \\
\text { structure }\end{array}$ & $\begin{array}{l}\text { Okubo et al. } \\
{[118,119]}\end{array}$ \\
\hline
\end{tabular}

Table 2. Characteristics required for designing microencapsulation-based self-healing polymeric materials.

\begin{tabular}{cl}
\hline Component & \multicolumn{1}{c}{ Characteristics } \\
\hline \multirow{3}{*}{ Corrosion inhibitor } & Stability and shelf-life \\
& Deliverability \\
& Reactivity \\
& Shrinkage \\
& Physical and mechanical properties \\
& Thermal stability \\
\hline \multirow{2}{*}{ Microcapsule shell wall } & Chemical compatibility \\
& Mechanical properties \\
& Dispersion \\
& Thermal stability \\
\hline & Solubility \\
& Chemical compatibility \\
& Reactivity \\
& Dispersion \\
& Thermal stability \\
\hline
\end{tabular}




\subsubsection{Effective Parameters and Challenges of Microcapsule Embedment for Corrosion Inhibition}

It is evident that application of self-healing coatings will be the most common and cost effective method of improving the corrosion protection. However, for the excellent fabrication of self-healing coatings several parameters must be considered such as inhibitor material, microcapsule diameter (size), microcapsule core and shell, microcapsules dispersion, presence of catalyst, coating application, coating thickness and coating matrix. Therefore, there is a growing need for investigation of effective parameters in microcapsule formation which is under intense study by various researchers. For example, Nesterova et al. [120] found that an increase in stirring rate, stirrer geometry, correct choice of temperature, and a high stabilizer concentration all can affect the microcapsule size. In capsules with irregular shape mechanical stability will be compromised and capsules will be unacceptable for a coating use. Another interesting and effective parameter which should be considered for obtaining self-healing property is the position of capsules in the coating matrix. Therefore, Kumar et al. [121,122] studied two methods of applying microcapsules in the primer layer: mixing to the primer before applying and sandwiching the microcapsules in the primer during application. Experimental results suggested that the microcapsules should be mixed into the paint formulations at the time of application.

In the other work by Cho et al. [113], two self-healing systems based on siloxane materials have been studied. First system consists of phase-separated polydimethylsiloxane (PDMS) healing agents and microencapsulated catalyst. The limitation of this system is the possible reaction between PDMS healing agent and coating matrix. In order to overcome this drawback, in the second system both catalyst and PDMS healing agent are encapsulated within urea-formaldehyde (UF) microcapsules. Their dual-capsule PDMS healing system showed no evidence of corrosion in the damaged area even after a long time exposure to the corrosive species. Although self-healing or autonomically healing micro cracks is a promising approach for extending the life of coating, still there are significant of unsolved challenges for optimization of the autonomous microcapsule system which is suitable for multiple healing actions.

\section{Evaluation of Corrosion Inhibitors Using Advanced Characterization Techniques}

Electrochemical methods are most commonly used techniques for the evaluation of the efficiency of corrosion inhibitors. The advantages of electrochemical methods are short measurement time and mechanistic information that they provide which help not only in the design of corrosion protection strategies but also in the design of new inhibitors. Although several electrochemical techniques may be used to study the performance of corrosion inhibitors, potentiodynamic polarization method and electrochemical impedance spectroscopy (EIS) can provide significant useful information, which makes them the most useful method for such study and the number of reports used this method for study of corrosion inhibition performance is limited. As an example, Otmacic Curkovic et al. studied the mechanism of the protective action of three imidazole-based (4-methyl-1-(p-tolyl)-imidazole, 4-methyl-1-(o-tolyl)-imidazole, and 4-methyl-1-phenyl imidazole) corrosion inhibitors on copper in $3 \% \mathrm{NaCl}$, using quartz crystal microbalance measurements [123]. This study confirmed that even slight changes in the molecular structure induce a significant effect on the inhibiting properties. Both tolyl-substituted 4-methyl imidazoles rapidly adsorbed onto the copper surface and decreased the copper corrosion rate while the phenyl-substituted 4-methyl imidazole slowly formed a protective 3D layer. On the other hand, the inhibiting effect of o-tolyl-substituted compound did not improve with time, while the inhibiting efficiency of the phenyl-substituted inhibitor increased with immersion time. Figure 12 presents the mass and the corrosion potential changes with respect to immersion period measured by QCM-D in the presence of (a) 4-methyl-1-(o-tolyl)-imidazole and (b) 4-methyl-1-phenyl imidazole. The use of better inhibitor (phenyl based imidazole) shows the increase of the mass of the electrode which is due to the formation of protective layer on the copper surface. However, very little work has been performed on GO/IL systems. 

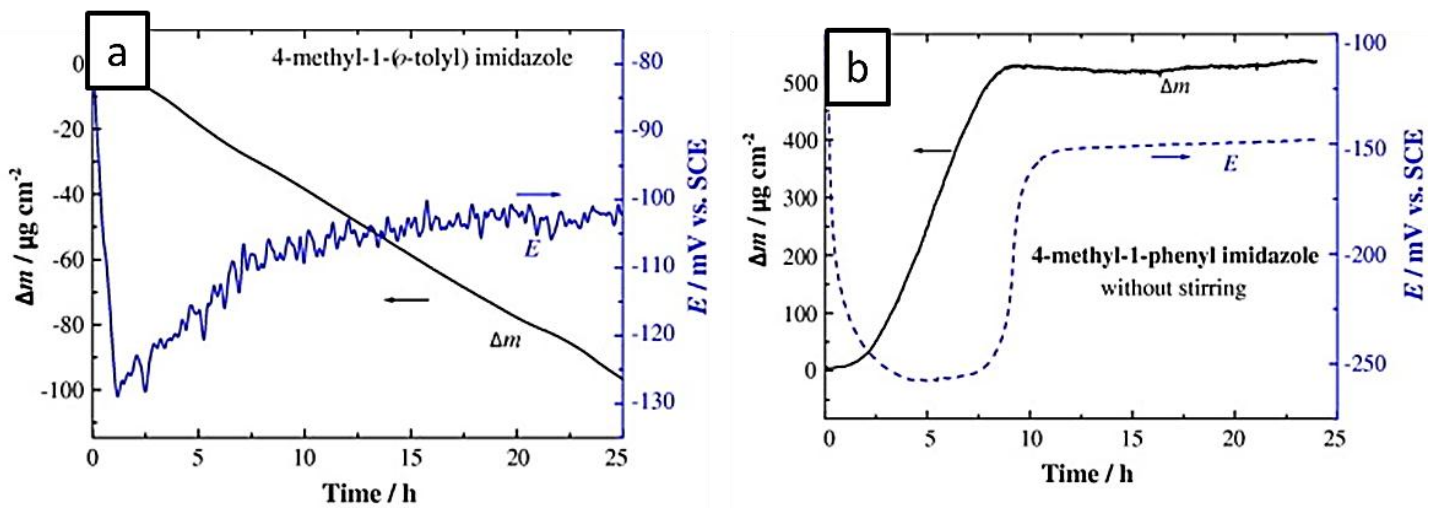

Figure 12. Mass and potential change of copper electrode in $3 \% \mathrm{NaCl}$ with the addition of (a) 4-methyl1-(p-tolyl)-imidazole and (b) 4-methyl-1-phenyl imidazole (Reprinted with permission from [123]. Copyright 2009 Elsevier).

On the other hand, the measurement of electrochemical reactions at the interface becomes a matter of particular interest for the prediction of the service life of coating. To achieve such information, new techniques that perform local measurements, such as scanning kelvin probe SKP are increasingly applied $[124,125]$. This method is a non-destructive, non-contact mode technique based on a vibrating capacitor to measure the surface work function (WF) distribution on the coating surface. Surface work function is an extremely sensitive indicator of the surface condition and can be used to track changes in the surface such as surface contamination and corrosive adhesion of polymers on metal substrates [126].

Among many studies, Choudhury et al. [127] recently presented the sol-gel derived hybrid coatings containing three different compositions of methacrylate-phosphosilicate on mild steel substrates where SKP microscopy was used to evaluate the adhesion and corrosion protection properties. Following equation can be used to correlate the absolute WF measured using $\operatorname{SKP}\left(V_{K P}\right)$ to the corrosion potential $\left(E_{\text {corr }}\right)[128]$ :

$$
V_{K P}=E_{\text {corr }}+\text { const. }
$$

Phosphorus containing methacrylate hybrids were synthesized from 2-(methacryloyloxy)ethyl phosphate (EGMP) and 3-[(methacryloyloxy)-propyl] trimethoxysilane (MEMO) via dual-cure process involving sol-gel reaction and addition polymerization. Similar experimental procedures were used to synthesize hybrids at other composition namely M:E-3:7 [129]. Figure 13 illustrates the SKP maps of the gold-coated aluminum (reference), bare metal substrate (MS), MEMO, EGMP, M:E-1:1 and M:E-3:7 coated samples. The average WF values of the samples shift positively towards noble potential in the order of bare MS < EGMP < MEMO < M:E-1:1 < M:E-3:7.

The deviation in WF values can be correlated to the interfacial interaction between the coating and the substrate. The SKP measurements showed the presence of strong interfacial interaction, which is attributed to the interaction of phosphate group with the metallic substrate [130].

An understanding of the correlation between the structure and observed corrosion inhibition properties, such as mechanism of adsorption, is essential for designing corrosion inhibitors with enhanced properties. Adsorption of an inhibitor on a metal surface depends on various parameters such as the nature and the surface charge of the metal, the inhibitor's chemical structure etc. One of the most common scattering techniques used for corrosion and corrosion inhibition study is surface-enhanced Raman scattering [131]. However, this technique studies the film that forms on the metal and is a surface analysis technique. 

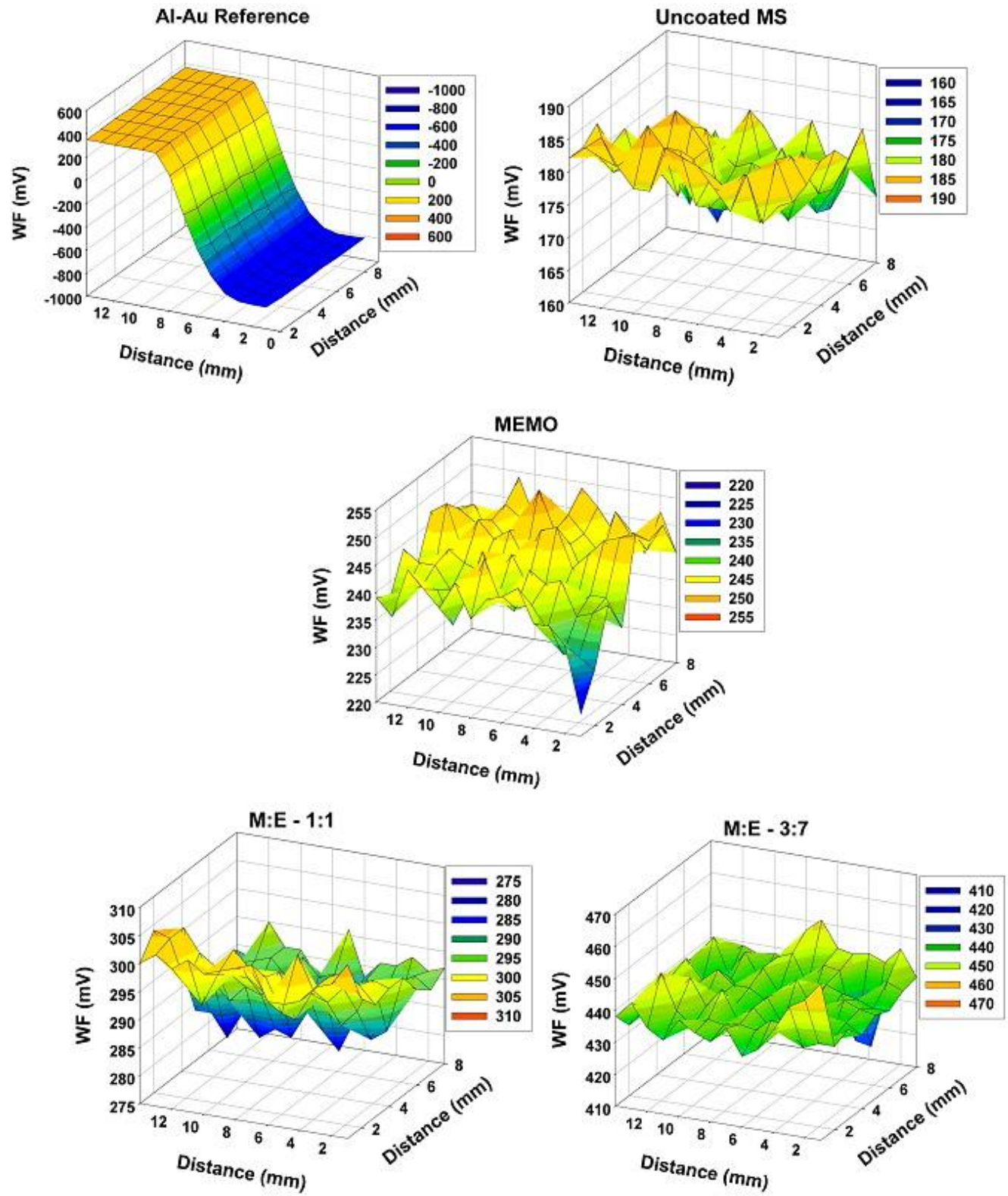

Figure 13. SKP maps of pristine gold on aluminum reference, bare MS, MEMO, M:E-1:1 and M:E-3:7 coated samples, respectively. (Reprinted with permission from [127]. Copyright 2010 Elsevier).

In the field of organic corrosion inhibitors, more attention is paid to the mechanism of adsorption and also to the relationship between inhibitor structures and their adsorption properties. Neutron scattering techniques including small angle neutron scattering (SANS) and ultra-small angle neutron scattering (USANS) are valuable techniques to study the structure of corrosion inhibitors in different forms including gels and nanoparticles. SANS and USANS are ideal and can be used to provide information relating to the crosslink porosity of structure, which is directly related to the mechanical properties of inhibitors. A literature survey of neutron scattering demonstrates that this technique has been employed to study the microstructure of a range of different types of polymers, predominantly from synthetic polymers. Furthermore, polymers studied by this method are classified into polymer blends, block copolymers and polymer gels [132].

Shibayama et al. [133] studied the structure of tetra-arm polyethylene glycol (PEG) gels by SANS. It has been investigated that there is no inhomogeneities appeared even by swelling. However, a steep upturn was observed in SANS curves, indicating the presence of PEG chain clusters or defects 
where these inhomogeneities disappear in swelled sample. Furthermore, Bhatia and co-workers designed a unique form of chemically cross-linked PEG gels to minimize defects in the network [134]. SANS was utilized to investigate the network structures of gels in two different solvents: $\mathrm{D}_{2} \mathrm{O}$ and d-DMF. SANS results show the resulting network structure is dependent on PEG length, transitioning from a more homogeneous network structure at high molecular weight PEG to a two phase structure at the lowest molecular weight PEG. It has been shown that with qualitative analysis and model fitting of SANS data, the highest molecular weight tetra-functional PEG hydrogels have a remarkably homogeneous network structure with low junction functionality. However, there are still some small indications of inhomogeneity for the lowest molecular weight networks even in d-DMF, suggesting a higher level of defect formation during cross-linking for these systems. Despite the extensive research on structural study of materials using SANS and USANS, to date there has not been any reports of using a combination of SANS and USANS to study the effect of corrosion inhibitors' structure on their efficiency. Recently, using combined USANS/SANS tools, Taghavikish et al. [74] investigated the hierarchical gel network structure and their relation to the observed bulk properties for polymeric ionic liquid nanoparticle emulsion based corrosion inhibitor in anticorrosion coatings.

\section{Conclusions and Future Outlook}

The importance of physico-chemical properties of the emerging corrosion inhibitors based on IL and graphene for corrosion prevention of metallic substrates were outlined. Despite the very interesting properties of ILs and graphene for corrosion inhibition, there have been very few reports on their application for corrosion protection of metals. On the other hand, in spite of the considerable progress made in the chemistry of inhibitors, the inhibition study in a corrosion system presents the same challenges today as it did in the past. The transport of the corrosion inhibitor from bulk solution to the surface of the metal and the active inhibitor species that is available to interact with the metal are the fundamental factors governing corrosion inhibition. In the case of inhibitors that adsorb on the metal surface and inhibit the corrosion, there are two main challenges: (1) metal-inhibitor interactions and (2) transport of the corrosion inhibitor from bulk solution to the surface of the metal. These challenges could be overcome through immobilization of corrosion inhibitors into micro-/nanocontainers.

Although active corrosion inhibitors lead to sufficient temporary protection of the underlying metal, in the case of local damage of the protective coating, to reach an even more extended lifetime protection or to have repeatable healing at a specific location, an additional functionality of damage closure is required. Therefore, there is a significant need to develop the new micro-/nanocapsules family which are sensitive to $\mathrm{pH}$, temperature, environmental conditions changes and dispersion of them to coatings should be considered.

Further research should also be focused on using more advanced characterization techniques and more fundamental studies in order to further clarify the mechanism of corrosion inhibitors and investigate the correlation between the structure and observed corrosion inhibition. This understanding will help us to tailor the inhibitor structure to obtain required corrosion inhibition properties. This would be more pronounced in the case of appropriate chemical modifications, especially by using eco-friendly inhibitors, which can render the coating with enhanced anticorrosive characteristics.

Acknowledgments: The authors gratefully acknowledge the financial support of the Australian Research Council's Linkage grant for carrying out this work and also the industry partner Wave rider Energy for financial support of this work.

Author Contributions: Namita Roy Choudhury, Mona Taghavikish and Naba Kumar Dutta designed the structure of the review. Mona Taghavikish wrote the review with Namita Roy Choudhury, Naba Kumar Dutta and the manuscript was finalized through contributions of all authors. All authors have given approval to the final version of the manuscript.

Conflicts of Interest: The authors declare no conflict of interest. 


\section{References}

1. Wazarkar, K.; Patil, D.; Rane, A.; Balgude, D.; Kathalewar, M.; Sabnis, A. Microencapsulation: An emerging technique in the modern coating industry. RSC Adv. 2016, 6, 106964-106979. [CrossRef]

2. Dariva, C.G.; Galio, A.F. Corrosion inhibitors-principles, mechanisms and applications. In Developments in Corrosion Protection; Aliofkhazraei, M., Ed.; INTECH: Winchester, UK, 2014; pp. 365-379.

3. Benali, O.; Cherkaoui, O.; Lallam, A. Adsorption and corrosion inhibition of new synthesized pyridaziniumbased ionic liquid on carbon steel in $0.5 \mathrm{MH}_{2} \mathrm{SO}_{4}$. J. Mater. Environ. Sci. 2015, 6, 598-606.

4. Saji, V.S. A review on recent patents in corrosion inhibitors. Recent Pat. Corros. Sci. 2010, 2, 6-12. [CrossRef]

5. Bardal, E. Corrosion and Protection; Springer Science \& Business Media: London, UK, 2007.

6. Yaro, A.S.; Khadom, A.A.; Wael, R.K. Apricot juice as green corrosion inhibitor of mild steel in phosphoric acid. Alex. Eng. J. 2013, 52, 129-135. [CrossRef]

7. Sherif, E.-S.M. Effects of 2-amino-5-(ethylthio)-1,3,4-thiadiazole on copper corrosion as a corrosion inhibitor in $3 \% \mathrm{NaCl}$ solutions. Appl. Surf. Sci. 2006, 252, 8615-8623. [CrossRef]

8. Revie, R.W. Corrosion and Corrosion Control, 4th ed.; John Wiley \& Sons: Hoboken, NJ, USA, 2008.

9. Olivares, O.; Likhanova, N.; Gomez, B.; Navarrete, J.; Llanos-Serrano, M.; Arce, E.; Hallen, J. Electrochemical and XPS studies of decylamides of $\alpha$-amino acids adsorption on carbon steel in acidic environment. Appl. Surf. Sci. 2006, 252, 2894-2909. [CrossRef]

10. Olivares-Xometl, O.; Likhanova, N.; Domínguez-Aguilar, M.; Arce, E.; Dorantes, H.; Arellanes-Lozada, P. Synthesis and corrosion inhibition of $\alpha$-amino acids alkylamides for mild steel in acidic environment. Mater. Chem. Phys. 2008, 110, 344-351. [CrossRef]

11. El-Maksoud, S.A.; Fouda, A. Some pyridine derivatives as corrosion inhibitors for carbon steel in acidic medium. Mater. Chem. Phys. 2005, 93, 84-90. [CrossRef]

12. Noor, E.A. Evaluation of inhibitive action of some quaternary N-heterocyclic compounds on the corrosion of Al-Cu alloy in hydrochloric acid. Mater. Chem. Phys. 2009, 114, 533-541. [CrossRef]

13. Martínez-Palou, R.; Rivera, J.; Zepeda, L.; Rodríguez, A.; Hernández, M.; Marín-Cruz, J.; Estrada, A. Evaluation of corrosion inhibitors synthesized from fatty acids and fatty alcohols isolated from sugar cane wax. Corrosion 2004, 60, 465-470. [CrossRef]

14. Olivares-Xometl, O.; Likhanova, N.; Martínez-Palou, R.; Domínguez-Aguilar, M. Electrochemistry and XPS study of an imidazoline as corrosion inhibitor of mild steel in an acidic environment. Mater. Corros. 2009, 60, 14-21. [CrossRef]

15. Popova, A.; Christov, M.; Zwetanova, A. Effect of the molecular structure on the inhibitor properties of azoles on mild steel corrosion in $1 \mathrm{~m}$ hydrochloric acid. Corros. Sci. 2007, 49, 2131-2143. [CrossRef]

16. Antonijević, M.M.; Milić, S.M.; Petrović, M.B. Films formed on copper surface in chloride media in the presence of azoles. Corros. Sci. 2009, 51, 1228-1237. [CrossRef]

17. Tallman, D.E.; Spinks, G.; Dominis, A.; Wallace, G.G. Electroactive conducting polymers for corrosion control. J. Solid State Electrochem. 2002, 6, 73-84. [CrossRef]

18. Hu, J.; Ji, Y.; Shi, Y.; Hui, F.; Duan, H.; Lanza, M. A review on the use of graphene as a protective coating against corrosion. Ann. Mater. Sci. Eng. 2014, 1, 16.

19. Martínez-Palou, R.; Sánche, P.F. Perspectives of Ionic Liquids Applications for Clean Oilfield Technologies; INTECH Open Access Publisher: Rijeka, Croatia, 2011.

20. Zhang, Q.; Hua, Y. Corrosion inhibition of mild steel by alkylimidazolium ionic liquids in hydrochloric acid. Electrochim. Acta 2009, 54, 1881-1887. [CrossRef]

21. Yuan, J.; Antonietti, M. Poly(ionic liquid)s: Polymers expanding classical property profiles. Polymer 2011, 52, 1469-1482. [CrossRef]

22. Plechkova, N.V.; Seddon, K.R. Applications of ionic liquids in the chemical industry. Chem. Soc. Rev. 2008, 37, 123-150. [CrossRef] [PubMed]

23. Olivier-Bourbigou, H.; Magna, L.; Morvan, D. Ionic liquids and catalysis: Recent progress from knowledge to applications. Appl. Catal. A General 2010, 373, 1-56. [CrossRef]

24. Han, X.; Armstrong, D.W. Ionic liquids in separations. Acc. Chem. Res. 2007, 40, 1079-1086. [CrossRef] [PubMed] 
25. Bara, J.E.; Carlisle, T.K.; Gabriel, C.J.; Camper, D.; Finotello, A.; Gin, D.L.; Noble, R.D. Guide to $\mathrm{CO}_{2}$ separations in imidazolium-based room-temperature ionic liquids. Ind. Eng. Chem. Res. 2009, 48, 2739-2751. [CrossRef]

26. Anderson, J.L.; Armstrong, D.W.; Wei, G.-T. Ionic liquids in analytical chemistry. Anal. Chem. 2006, 78, 2892-2902. [CrossRef] [PubMed]

27. Wang, H.; Lu, Q.; Ye, C.; Liu, W.; Cui, Z. Friction and wear behaviors of ionic liquid of alkylimidazolium hexafluorophosphates as lubricants for steel/steel contact. Wear 2004, 256, 44-48. [CrossRef]

28. Kuang, D.; Wang, P.; Ito, S.; Zakeeruddin, S.M.; Grätzel, M. Stable mesoscopic dye-sensitized solar cells based on tetracyanoborate ionic liquid electrolyte. J. Am. Chem. Soc. 2006, 128, 7732-7733. [CrossRef] [PubMed]

29. Likhanova, N.V.; Domínguez-Aguilar, M.A.; Olivares-Xometl, O.; Nava-Entzana, N.; Arce, E.; Dorantes, H. The effect of ionic liquids with imidazolium and pyridinium cations on the corrosion inhibition of mild steel in acidic environment. Corros. Sci. 2010, 52, 2088-2097. [CrossRef]

30. Łuczak, J.; Hupka, J.; Thöming, J.; Jungnickel, C. Self-organization of imidazolium ionic liquids in aqueous solution. Colloids Surf. A Physicochem. Eng. Asp. 2008, 329, 125-133. [CrossRef]

31. Espinosa, T.; Sanes, J.; Jiménez, A.-E.; Bermúdez, M.-D. Surface interactions, corrosion processes and lubricating performance of protic and aprotic ionic liquids with ofhc copper. Appl. Surf. Sci. 2013, 273, 578-597. [CrossRef]

32. Elachouri, M.; Hajji, M.; Kertit, S.; Essassi, E.; Salem, M.; Coudert, R. Some surfactants in the series of 2-(alkyldimethylammonio) alkanol bromides as inhibitors of the corrosion of iron in acid chloride solution. Corros. Sci. 1995, 37, 381-389. [CrossRef]

33. Quraishi, M.A.; Rafiquee, M.Z.A.; Khan, S.; Saxena, N. Corrosion inhibition of aluminium in acid solutions by some imidazoline derivatives. J. Appl. Electrochem. 2007, 37, 1153-1162. [CrossRef]

34. Gasparac, R.; Martin, C.; Stupnisek-Lisac, E. In situ studies of imidazole and its derivatives as copper corrosion inhibitors. I. Activation energies and thermodynamics of adsorption. J. Electrochem. Soc. 2000, 147, 548-551. [CrossRef]

35. Zhang, D.-Q.; Gao, L.-X.; Zhou, G.-D. Inhibition of copper corrosion by bis-(1,1'-benzotriazoly)- $\alpha, \omega$-diamide compounds in aerated sulfuric acid solution. Appl. Surf. Sci. 2006, 252, 4975-4981. [CrossRef]

36. Zhang, Q.; Hua, Y. Corrosion inhibition of aluminum in hydrochloric acid solution by alkylimidazolium ionic liquids. Mater. Chem. Phys. 2010, 119, 57-64. [CrossRef]

37. Shuncun, S.; Pinggui, Y.; Chenzhong, C.; Xueye, W.; Jieshu, S.; Junxi, L. Synthesis of new ionic liquids and corrosion inhibition performance of its cationic imidazoline group. J. Chem. Ind. Eng. China 2005, 56, 1112-1119.

38. Ford, F.; Burstein, G.; Hoar, T. Bare surface reaction rates and their relation to environment controlled cracking of aluminum alloys I. Bare surface reaction rates on aluminum-7 weight percent magnesium in aqueous solutions. J. Electrochem. Soc. 1980, 127, 1325-1331. [CrossRef]

39. Uerdingen, M.; Treber, C.; Balser, M.; Schmitt, G.; Werner, C. Corrosion behaviour of ionic liquids. Green Chem. 2005, 7, 321-325. [CrossRef]

40. Ashassi-Sorkhabi, H.; Es'haghi, M. Corrosion inhibition of mild steel in acidic media by [BMIm]Br ionic liquid. Mater. Chem. Phys. 2009, 114, 267-271. [CrossRef]

41. Chong, A.L.; Mardel, J.I.; MacFarlane, D.R.; Forsyth, M.; Somers, A.E. Synergistic corrosion inhibition of mild steel in aqueous chloride solutions by an imidazolinium carboxylate salt. ACS Sustain. Chem. Eng. 2016, 4, 1746-1755. [CrossRef]

42. Zhang, H.; Hong, K.; Mays, J.W. Synthesis of block copolymers of styrene and methyl methacrylate by conventional free radical polymerization in room temperature ionic liquids. Macromolecules 2002, 35, 5738-5741. [CrossRef]

43. Woecht, I.; Schmidt-Naake, G.; Beuermann, S.; Buback, M.; García, N. Propagation kinetics of free-radical polymerizations in ionic liquids. J. Polym. Sci. Part A Polym. Chem. 2008, 46, 1460-1469. [CrossRef]

44. Ricks-Laskoski, H.L.; Snow, A.W. Synthesis and electric field actuation of an ionic liquid polymer. J. Am. Chem. Soc. 2006, 128, 12402-12403. [CrossRef] [PubMed]

45. Green, O.; Grubjesic, S.; Lee, S.; Firestone, M.A. The design of polymeric ionic liquids for the preparation of functional materials. Polym. Rev. 2009, 49, 339-360. [CrossRef]

46. Anderson, E.B.; Long, T.E. Imidazole- and imidazolium-containing polymers for biology and material science applications. Polymer 2010, 51, 2447-2454. [CrossRef] 
47. Green, M.D.; Long, T.E. Designing imidazole-based ionic liquids and ionic liquid monomers for emerging technologies. Polym. Rev. 2009, 49, 291-314. [CrossRef]

48. Shaplov, A.S.; Vlasov, P.S.; Lozinskaya, E.I.; Shishkan, O.A.; Ponkratov, D.O.; Malyshkina, I.A.; Vidal, F.; Wandrey, C.; Godovikov, I.A.; Vygodskii, Y.S. Thiol-ene click chemistry as a tool for a novel family of polymeric ionic liquids. Macromol. Chem. Phys. 2012, 213, 1359-1369. [CrossRef]

49. Shaplov, A.S.; Goujon, L.; Vidal, F.; Lozinskaya, E.I.; Meyer, F.; Malyshkina, I.A.; Chevrot, C.; Teyssie, D.; Odinets, I.L.; Vygodskii, Y.S. Ionic IPNs as novel candidates for highly conductive solid polymer electrolytes. J. Polym. Sci. Part A Polym. Chem. 2009, 47, 4245-4266. [CrossRef]

50. Allen, M.H.; Green, M.D.; Getaneh, H.K.; Miller, K.M.; Long, T.E. Tailoring charge density and hydrogen bonding of imidazolium copolymers for efficient gene delivery. Biomacromolecules 2011, 12, 2243-2250. [CrossRef] [PubMed]

51. Qiu, B.; Lin, B.; Si, Z.; Qiu, L.; Chu, F.; Zhao, J.; Yan, F. Bis-imidazolium-based anion-exchange membranes for alkaline fuel cells. J. Power Sources 2012, 217, 329-335. [CrossRef]

52. Mecerreyes, D. Polymeric ionic liquids: Broadening the properties and applications of polyelectrolytes. Prog. Polym. Sci. 2011, 36, 1629-1648. [CrossRef]

53. Arellanes-Lozada, P.; Olivares-Xometl, O.; Guzmán-Lucero, D.; Likhanova, N.V.; Domínguez-Aguilar, M.A.; Lijanova, I.V.; Arce-Estrada, E. The inhibition of aluminum corrosion in sulfuric acid by poly (1-vinyl-3-alkylimidazolium hexafluorophosphate). Materials 2014, 7, 5711-5734. [CrossRef] [PubMed]

54. Atta, A.M.; El-Mahdy, G.A.; Allohedan, H.A.; Abdullah, M.M. Poly (ionic liquid) based on modified ionic polyacrylamide for inhibition steel corrosion in acid solution. Int. J. Electrochem. Sci. 2015, 10, 10389-10401.

55. Borisova, D.; Akçakayıran, D.; Schenderlein, M.; Möhwald, H.; Shchukin, D.G. Nanocontainer-based anticorrosive coatings: Effect of the container size on the self-healing performance. Adv. Funct. Mater. 2013, 23, 3799-3812. [CrossRef]

56. Abdelhedi-Miladi, I.; Obadia, M.M.; Allaoua, I.; Serghei, A.; Romdhane, H.B.; Drockenmuller, E. 1,2,3triazolium-based poly(ionic liquid)s obtained through click chemistry polyaddition. Macromol. Chem. Phys. 2014, 215, 2229-2236. [CrossRef]

57. Stepto Robert, F.T. Dispersity in polymer science (IUPAC recommendations 2009). Pure Appl. Chem. 2009, 81, 351-353. [CrossRef]

58. Muldoon, M.J.; Gordon, C.M. Synthesis of gel-type polymer beads from ionic liquid monomers. J. Polym. Sci. Part A Polym. Chem. 2004, 42, 3865-3869. [CrossRef]

59. Marcilla, R.; Sanchez-Paniagua, M.; Lopez-Ruiz, B.; Lopez-Cabarcos, E.; Ochoteco, E.; Grande, H.; Mecerreyes, D. Synthesis and characterization of new polymeric ionic liquid microgels. J. Polym. Sci. Part A Polym. Chem. 2006, 44, 3958-3965. [CrossRef]

60. Yuan, J.; Antonietti, M. Poly(ionic liquid) latexes prepared by dispersion polymerization of ionic liquid monomers. Macromolecules 2011, 44, 744-750. [CrossRef]

61. Yuan, J.; Soll, S.; Drechsler, M.; Müller, A.H.E.; Antonietti, M. Self-assembly of poly(ionic liquid)s: Polymerization, mesostructure formation, and directional alignment in one step. J. Am. Chem. Soc. 2011, 133, 17556-17559. [CrossRef] [PubMed]

62. Weber, R.L.; Ye, Y.; Schmitt, A.L.; Banik, S.M.; Elabd, Y.A.; Mahanthappa, M.K. Effect of nanoscale morphology on the conductivity of polymerized ionic liquid block copolymers. Macromolecules 2011, 44, 5727-5735. [CrossRef]

63. Yang, J.; Qiu, L.; Liu, B.; Peng, Y.; Yan, F.; Shang, S. Synthesis of polymeric ionic liquid microsphere/Pt nanoparticle hybrids for electrocatalytic oxidation of methanol and catalytic oxidation of benzyl alcohol. J. Polym. Sci. Part A Polym. Chem. 2011, 49, 4531-4538. [CrossRef]

64. Zhou, X.; Zhou, Y.; Nie, J.; Ji, Z.; Xu, J.; Zhang, X.; Du, B. Thermosensitive ionic microgels via surfactant-free emulsion copolymerization and in situ quaternization cross-linking. ACS Appl. Mater. Interfaces 2014, 6, 4498-4513. [CrossRef] [PubMed]

65. Amato, D.V.; Amato, D.N.; Flynt, A.S.; Patton, D.L. Functional, sub-100 nm polymer nanoparticles via thiol-ene miniemulsion photopolymerization. Polym. Chem. 2015, 6, 5625-5632. [CrossRef]

66. Hoyle, C.E.; Lee, T.Y.; Roper, T. Thiol-enes: Chemistry of the past with promise for the future. J. Polym. Sci. Part A Polym. Chem. 2004, 42, 5301-5338. [CrossRef]

67. Hoyle, C.E.; Lowe, A.B.; Bowman, C.N. Thiol-click chemistry: A multifaceted toolbox for small molecule and polymer synthesis. Chem. Soc. Rev. 2010, 39, 1355-1387. [CrossRef] [PubMed] 
68. Jasinski, F.; Lobry, E.; Tarablsi, B.; Chemtob, A.; Croutxé-Barghorn, C.; Le Nouen, D.; Criqui, A. Light-mediated thiol-ene polymerization in miniemulsion: A fast route to semicrystalline polysulfide nanoparticles. ACS Macro Lett. 2014, 3, 958-962. [CrossRef]

69. Taghavikish, M.; Subianto, S.; Dutta, N.K.; de Campo, L.; Mata, J.P.; Rehm, C.; Choudhury, N.R. Polymeric ionic liquid nanoparticle emulsions as a corrosion inhibitor in anticorrosion coatings. ACS Omega 2016, 1, 29-40. [CrossRef]

70. Raghavan, P.; Manuel, J.; Zhao, X.; Kim, D.-S.; Ahn, J.-H.; Nah, C. Preparation and electrochemical characterization of gel polymer electrolyte based on electrospun polyacrylonitrile nonwoven membranes for lithium batteries. J. Power Sources 2011, 196, 6742-6749. [CrossRef]

71. Murata, Y.; Sasaki, N.; Miyamoto, E.; Kawashima, S. Use of floating alginate gel beads for stomach-specific drug delivery. Eur. J. Pharm. Biopharm. 2000, 50, 221-226. [CrossRef]

72. Kashyap, N.; Kumar, N.; Kumar, M.N.V.R. Hydrogels for pharmaceutical and biomedical applications. Crit. Rev. Ther. Drug Carr. Syst. 2005, 22, 107-149. [CrossRef]

73. Xiong, Y.; Wang, H.; Wang, R.; Yan, Y.; Zheng, B.; Wang, Y. A facile one-step synthesis to cross-linked polymeric nanoparticles as highly active and selective catalysts for cycloaddition of $\mathrm{CO}_{2}$ to epoxides. Chem. Commun. 2010, 46, 3399-3401. [CrossRef] [PubMed]

74. Rahman, M.T.; Barikbin, Z.; Badruddoza, A.Z.M.; Doyle, P.S.; Khan, S.A. Monodisperse polymeric ionic liquid microgel beads with multiple chemically switchable functionalities. Langmuir 2013, 29, 9535-9543. [CrossRef] [PubMed]

75. Taghavikish, M.; Subianto, S.; Dutta, N.K.; Choudhury, N.R. Facile fabrication of polymerizable ionic liquid based-gel beads via thiol-ene chemistry. ACS Appl. Mater. Interfaces 2015, 7, 17298-17306. [CrossRef] [PubMed]

76. Graphene. Available online: https://www.graphene-info.com/introduction (accessed on 24 October 2017).

77. Prasai, D.; Tuberquia, J.C.; Harl, R.R.; Jennings, G.K.; Bolotin, K.I. Graphene: Corrosion-inhibiting coating. ACS Nano 2012, 6, 1102-1108. [CrossRef] [PubMed]

78. Zhu, Y.; Murali, S.; Cai, W.; Li, X.; Suk, J.W.; Potts, J.R.; Ruoff, R.S. Graphene and graphene oxide: Synthesis, properties, and applications. Adv. Mater. 2010, 22, 3906-3924. [CrossRef] [PubMed]

79. Qiu, J.; Wang, S. Enhancing polymer performance through graphene sheets. J. Appl. Polym. Sci. 2011, 119, 3670-3674. [CrossRef]

80. Lee, C.; Wei, X.; Kysar, J.W.; Hone, J. Measurement of the elastic properties and intrinsic strength of monolayer graphene. Science 2008, 321, 385-388. [CrossRef] [PubMed]

81. Balandin, A.A.; Ghosh, S.; Bao, W.; Calizo, I.; Teweldebrhan, D.; Miao, F.; Lau, C.N. Superior thermal conductivity of single-layer graphene. Nano Lett. 2008, 8, 902-907. [CrossRef] [PubMed]

82. Cheng, J.; Zhang, G.; Du, J.; Tang, L.; Xu, J.; Li, J. New role of graphene oxide as active hydrogen donor in the recyclable palladium nanoparticles catalyzed ullmann reaction in environmental friendly ionic liquid/supercritical carbon dioxide system. J. Mater. Chem. 2011, 21, 3485-3494. [CrossRef]

83. Song, H.; Zhang, L.; He, C.; Qu, Y.; Tian, Y.; Lv, Y. Graphene sheets decorated with $\mathrm{SnO}_{2}$ nanoparticles: In situ synthesis and highly efficient materials for cataluminescence gas sensors. J. Mater. Chem. 2011, 21, 5972-5977. [CrossRef]

84. Zhao, J.; Pei, S.; Ren, W.; Gao, L.; Cheng, H.-M. Efficient preparation of large-area graphene oxide sheets for transparent conductive films. ACS Nano 2010, 4, 5245-5252. [CrossRef] [PubMed]

85. Liang, M.; Zhi, L. Graphene-based electrode materials for rechargeable lithium batteries. J. Mater. Chem. 2009, 19, 5871-5878. [CrossRef]

86. Reddy, A.L.M.; Srivastava, A.; Gowda, S.R.; Gullapalli, H.; Dubey, M.; Ajayan, P.M. Synthesis of nitrogen-doped graphene films for lithium battery application. ACS Nano 2010, 4, 6337-6342. [CrossRef] [PubMed]

87. Zhang, K.; Zhang, L.L.; Zhao, X.S.; Wu, J. Graphene/polyaniline nanofiber composites as supercapacitor electrodes. Chem. Mater. 2010, 22, 1392-1401. [CrossRef]

88. Kalita, G.; Matsushima, M.; Uchida, H.; Wakita, K.; Umeno, M. Graphene constructed carbon thin films as transparent electrodes for solar cell applications. J. Mater. Chem. 2010, 20, 9713-9717. [CrossRef]

89. Ramanathan, T.; Abdala, A.A.; Stankovich, S.; Dikin, D.A.; Herrera Alonso, M.; Piner, R.D.; Adamson, D.H.; Schniepp, H.C.; Chen, X.; Ruoff, R.S.; et al. Functionalized graphene sheets for polymer nanocomposites. Nat. Nanotechnol. 2008, 3, 327-331. [CrossRef] [PubMed] 
90. Salavagione, H.J.; Martinez, G.; Gomez, M.A. Synthesis of poly(vinyl alcohol)/reduced graphite oxide nanocomposites with improved thermal and electrical properties. J. Mater. Chem. 2009, 19, 5027-5032. [CrossRef]

91. Cai, D.; Song, M. Recent advance in functionalized graphene/polymer nanocomposites. J. Mater. Chem. 2010, 20, 7906-7915. [CrossRef]

92. Zhu, J. Graphene production: New solutions to a new problem. Nat Nano 2008, 3, 528-529. [CrossRef] [PubMed]

93. Chang, C.-H.; Huang, T.-C.; Peng, C.-W.; Yeh, T.-C.; Lu, H.-I.; Hung, W.-I.; Weng, C.-J.; Yang, T.-I.; Yeh, J.-M. Novel anticorrosion coatings prepared from polyaniline/graphene composites. Carbon 2012, 50, 5044-5051. [CrossRef]

94. Yasmin, A.; Daniel, I.M. Mechanical and thermal properties of graphite platelet/epoxy composites. Polymer 2004, 45, 8211-8219. [CrossRef]

95. Rafiee, M.A.; Rafiee, J.; Wang, Z.; Song, H.; Yu, Z.Z.; Koratkar, N. Enhanced mechanical properties of nanocomposites at low graphene content. ACS Nano 2009, 3, 3884-3890. [CrossRef] [PubMed]

96. Miller, S.G.; Bauer, J.L.; Maryanski, M.J.; Heimann, P.J.; Barlow, J.P.; Gosau, J.M.; Allred, R.E. Characterization of epoxy functionalized graphite nanoparticles and the physical properties of epoxy matrix nanocomposites. Compos. Sci. Technol. 2010, 70, 1120-1125. [CrossRef]

97. Chiang, C.L.; Hsu, S.W. Synthesis, characterization and thermal properties of novel epoxy/expandable graphite composites. Polym. Int. 2010, 59, 119-126. [CrossRef]

98. Martin-Gallego, M.; Verdejo, R.; Lopez-Manchado, M.A.; Sangermano, M. Epoxy-graphene UV-cured nanocomposites. Polymer 2011, 52, 4664-4669. [CrossRef]

99. Sørensen, P.A.; Kiil, S.; Dam-Johansen, K.; Weinell, C.E. Anticorrosive coatings: A review. J. Coat. Technol. Res. 2009, 6, 135-176. [CrossRef]

100. Bao, C.; Guo, Y.; Song, L.; Kan, Y.; Qian, X.; Hu, Y. In situ preparation of functionalized graphene oxide/epoxy nanocomposites with effective reinforcements. J. Mater. Chem. 2011, 21, 13290-13298. [CrossRef]

101. Borisova, D.; Möhwald, H.; Shchukin, D.G. Mesoporous silica nanoparticles for active corrosion protection. ACS Nano 2011, 5, 1939-1946. [CrossRef] [PubMed]

102. Shchukin, D.G.; Grigoriev, D.O.; Mohwald, H. Application of smart organic nanocontainers in feedback active coatings. Soft Matter 2010, 6, 720-725. [CrossRef]

103. Dry, C. Procedures developed for self-repair of polymer matrix composite materials. Compos. Struct. 1996, 35, 263-269. [CrossRef]

104. Dry, C.M.; Sottos, N.R. Passive smart self-repair in polymer matrix composite materials. Proc. SPIE Int. Soc. Opt. Eng. 1993, 1916, 438-444.

105. Zhang, M.Q.; Rong, M.Z. Intrinsic self-healing of covalent polymers through bond reconnection towards strength restoration. Polym. Chem. 2013, 4, 4878-4884. [CrossRef]

106. Chen, Y.; Kushner, A.M.; Williams, G.A.; Guan, Z. Multiphase design of autonomic self-healing thermoplastic elastomers. Nat. Chem. 2012, 4, 467-472. [CrossRef] [PubMed]

107. Kessler, M.R. Self-healing: A new paradigm in materials design. Proc. Inst. Mech. Eng. Part G J. Aerosp. Eng. 2007, 221, 479-495. [CrossRef]

108. Lvov, Y.M.; Shchukin, D.G.; Möhwald, H.; Price, R.R. Halloysite clay nanotubes for controlled release of protective agents. ACS Nano 2008, 2, 814-820. [CrossRef] [PubMed]

109. Agnihotri, N.; Mishra, R.; Goda, C.; Arora, M. Microencapsulation-A novel approach in drug delivery: A review. Indo Glob. J. Pharm. Sci. 2012, 2, 1-20.

110. Liu, X.; Zhang, H.; Wang, J.; Wang, Z.; Wang, S. Preparation of epoxy microcapsule based self-healing coatings and their behavior. Surf. Coat. Technol. 2012, 206, 4976-4980. [CrossRef]

111. Huang, M.; Zhang, H.; Yang, J. Synthesis of organic silane microcapsules for self-healing corrosion resistant polymer coatings. Corros. Sci. 2012, 65, 561-566. [CrossRef]

112. Brown, E.N.; Kessler, M.R.; Sottos, N.R.; White, S.R. In situ poly(urea-formaldehyde) microencapsulation of dicyclopentadiene. J. Microencapsul. 2003, 20, 719-730. [CrossRef] [PubMed]

113. Cho, S.H.; White, S.R.; Braun, P.V. Self-healing polymer coatings. Adv. Mater. 2009, 21, 645-649. [CrossRef]

114. Samadzadeh, M.; Boura, S.H.; Peikari, M.; Kasiriha, S.M.; Ashrafi, A. A review on self-healing coatings based on micro/nanocapsules. Prog. Org. Coat. 2010, 68, 159-164. [CrossRef] 
115. Wilson, G.O.; Andersson, H.M.; White, S.R.; Sottos, N.R.; Moore, J.S.; Braun, P.V. Self-healing polymers. In Encyclopedia of Polymer Science and Technology; John Wiley \& Sons, Inc.: New York, NY, USA, 2002.

116. Bandeira, P.; Monteiro, J.; Baptista, A.M.; Magalhães, F.D. Tribological performance of PTFE-based coating modified with microencapsulated [HMIM][NTf2] ionic liquid. Tribol. Lett. 2015, 59, 1-15. [CrossRef]

117. García, S.J.; Fischer, H.R.; White, P.A.; Mardel, J.; González-García, Y.; Mol, J.M.C.; Hughes, A.E. Self-healing anticorrosive organic coating based on an encapsulated water reactive silyl ester: Synthesis and proof of concept. Prog. Org. Coat. 2011, 70, 142-149. [CrossRef]

118. Minami, H.; Fukaumi, H.; Okubo, M.; Suzuki, T. Preparation of ionic liquid-encapsulated polymer particles. Colloid Polym. Sci. 2013, 291, 45-51. [CrossRef]

119. Minami, H.; Okubo, M.; Oshima, Y. Preparation of cured epoxy resin particles having one hollow by polyaddition reaction. Polymer 2005, 46, 1051-1056. [CrossRef]

120. Nesterova, T.; Dam-Johansen, K.; Pedersen, L.T.; Kiil, S. Microcapsule-based self-healing anticorrosive coatings: Capsule size, coating formulation, and exposure testing. Prog. Org. Coat. 2012, 75, 309-318. [CrossRef]

121. Mehta, N.K.; Bogere, M.N. Environmental studies of smart/self-healing coating system for steel. Prog. Org. Coat. 2009, 64, 419-428. [CrossRef]

122. Kumar, A.; Mathur, N. Photocatalytic degradation of aniline at the interface of $\mathrm{TiO}_{2}$ suspensions containing carbonate ions. J. Colloid Interface Sci. 2006, 300, 244-252. [CrossRef] [PubMed]

123. Otmacic Curkovic, H.; Stupnisek-Lisac, E.; Takenouti, H. Electrochemical quartz crystal microbalance and electrochemical impedance spectroscopy study of copper corrosion inhibition by imidazoles. Corros. Sci. 2009, 51, 2342-2348. [CrossRef]

124. Dornbusch, M. The use of modern electrochemical methods in the development of corrosion protective coatings. Prog. Org. Coat. 2008, 61, 240-244. [CrossRef]

125. Nazarov, A.; Prosek, T.; Thierry, D. Application of EIS and SKP methods for the study of the zinc/polymer interface. Electrochim. Acta 2008, 53, 7531-7538. [CrossRef]

126. Wapner, K.; Stratmann, M.; Grundmeier, G. Application of the scanning kelvin probe for the study of the corrosion resistance of interfacial thin organosilane films at adhesive/metal interfaces. Silicon Chem. 2005, 2, 235-245. [CrossRef]

127. Kannan, A.G.; Choudhury, N.R.; Dutta, N.K. Electrochemical performance of sol-gel derived phospho-silicate-methacrylate hybrid coatings. J. Electroanal. Chem. 2010, 641, 28-34. [CrossRef]

128. Kannan, A.G.; Choudhury, N.R.; Dutta, N.K. Synthesis and characterization of methacrylate phospho-silicate hybrid for thin film applications. Polymer 2007, 48, 7078-7086. [CrossRef]

129. Stratmann, M. The investigation of the corrosion properties of metals, covered with adsorbed electrolyte layers-A new experimental technique. Corros. Sci. 1987, 27, 869-872. [CrossRef]

130. Pepe, A.; Galliano, P.; Aparicio, M.; Durán, A.; Ceré, S. Sol-gel coatings on carbon steel: Electrochemical evaluation. Surf. Coat. Technol. 2006, 200, 3486-3491. [CrossRef]

131. Sherif, E.-S.M.; Erasmus, R.M.; Comins, J.D. In situ raman spectroscopy and electrochemical techniques for studying corrosion and corrosion inhibition of iron in sodium chloride solutions. Electrochim. Acta 2010, 55, 3657-3663. [CrossRef]

132. Shibayama, M. Small-angle neutron scattering on polymer gels: Phase behavior, inhomogeneities and deformation mechanisms. Polym. J. 2011, 43, 18-34. [CrossRef]

133. Matsunaga, T.; Sakai, T.; Akagi, Y.; Chung, U.-I.; Shibayama, M. SANS and SLS studies on Tetra-Arm PEG gels in as-prepared and swollen states. Macromolecules 2009, 42, 6245-6252. [CrossRef]

134. Saffer, E.M.; Lackey, M.A.; Griffin, D.M.; Kishore, S.; Tew, G.N.; Bhatia, S.R. Sans study of highly resilient poly (ethylene glycol) hydrogels. Soft Matter 2014, 10, 1905-1916. [CrossRef] [PubMed]

(C) 2017 by the authors. Licensee MDPI, Basel, Switzerland. This article is an open access article distributed under the terms and conditions of the Creative Commons Attribution (CC BY) license (http:/ / creativecommons.org/licenses/by/4.0/). 